\title{
CAR-T cell therapy: current advances and future research possibilities
}

\author{
Manal M.E. Ahmed \\ Pharmacology Department, National Research Centre, Dokki, Giza, Egypt.
}

\begin{tabular}{|c|c|}
\hline Article Info & Abstract \\
\hline Article history: & Purpose: The aim is to review the current advances in designing safer and \\
\hline Recei & more efficient CAR-T cells and discuss the future research possibilities for \\
\hline & the treatment of both hematological malignancies and solid tumors. \\
\hline Acc & $\begin{array}{l}\text { Study Design: An extensive review was carried out on the basic structure of } \\
\text { CARS, current advances to design safer and more efficient CAR-T cells, and }\end{array}$ \\
\hline $\begin{array}{l}\text { Keywords: } \\
\text { CAR-T cell. }\end{array}$ & $\begin{array}{l}\text { future research possibilities for the treatment of both hematological } \\
\text { malignancies and solid tumors. }\end{array}$ \\
\hline Immunother & Results: Encouragement of chimeric \\
\hline Hematological alignancies, & therapy as one of adoptive immunotherapy is increasingly importa \\
\hline $\begin{array}{l}\text { Solid tumors, } \\
\text { Tumor microenvironment. }\end{array}$ & $\begin{array}{l}\text { recent years. Its preparation is based on thegenetic modification of } \\
\text { individual } T \text { cells. The innovation of the functional intracellular signaling }\end{array}$ \\
\hline & domain is a critical part of the genetically modified $T$ cells and requires a \\
\hline Paper Ty & long journey of development that has resulted in several improvements in the \\
\hline Revieı & safety and effectiveness of CAR-T cells. CAR-T cell therapy can be modified \\
\hline Corresponde & $\begin{array}{l}\text { rapidly and has great and strong application potential according to a large } \\
\text { number of global clinical trials. This article briefly describes the basic }\end{array}$ \\
\hline Manal M.E. Ahmed & $\begin{array}{l}\text { structure and design of CARs and discusses current trends in the } \\
\text { development of safer and more efficient CAR-T cells for the treatment of both }\end{array}$ \\
\hline $\begin{array}{l}\text { Email: } \\
\text { thinktankteam2014@gmail.cc }\end{array}$ & $\begin{array}{l}\text { hematological and solid malignancies and looks forward to future research } \\
\text { possibilities. }\end{array}$ \\
\hline & $\begin{array}{l}\text { Conclusion: It is concluded that conclude that the prospect of this } \\
\text { technology lies in CAR-T cell engineering which can overcome aggressive } \\
\text { TMEs and recruiting an endogenous tumor response. The final task for } \\
\text { researchers in this field is to carry out clinical trials and secure the funding } \\
\text { needed to complete their clinical trials. This immunotherapy continues to } \\
\text { progress and more records of successful malignancy eradication occur. }\end{array}$ \\
\hline
\end{tabular}

\section{Introduction}

The growing incidence of malignant tumorhas increased worldwide that threatens individual healthand society in both respects. Management approaches have shifted from traditional medicine including surgery, radiotherapy, and chemotherapy to adoptive immunotherapy that demonstrates greater efficacy and precision. Treatment using immunotherapy provides different techniques such as monoclonal antibodies (Mab), therapeutic vaccines, immune checkpoint inhibitors, and adoptive cell transfer (ACT) like T cell receptor (TCR) expressing $\mathrm{T}$ cell infusion and chimeric antigen receptor (CAR) expressing $\mathrm{T}$ cell infusion. Recent years have seen many improvements in thedevelopmentof CAR-T cell therapy very speedily (Ott et al., 2017; Hoos, 2016; Hedrick, 1993 and Mitchison, 1955). The main role of CAR-T cells is to help the patient's immune system to kill 
cancerous cells. The engineering of CAR-T cells to kill cancerous cells is performed by modification of an individual'sT cells. Simply, each CAR-T cell has a single-chain, extracellular variable fragment ( $\mathrm{scFv}$ ). It functions as a specific antigen receptor that enables the identification of a particular antigen directly without any need for a major histocompatibility complex (MHC). CAR-T cells have a wide range of applications inhematological cancers management (e.g., B-cell acute lymphoblastic leukemia (B-ALL), Bcell non-Hodgkin lymphoma (B-NHL), B-cell chronic lymphoblastic leukemia (B-CLL), and multiple myeloma (MM) (Locke, 2017; Turtle et al., 2017; Ali et al., 2016; Tang et al., 2016 and Porter et al., 2015), and have proven impressive effectiveness.

Food and Drug Administration (FDA) has approved Anti-CD19 CAR-T cell therapy for the treatment of relapsed / refractory B-ALL and diffused large B cell lymphoma (DLBCL). The progression in CAR-T cells is not only in the research sector that is being tested in a handful of research centers but has extended to the commercialized immunotherapy that is now incorporated into the standard cancer care. Despite this advancement, there are some significant challenges still facing CAR-T cells such as restricted usage in certain forms of B-cell malignancies with no extension to other hematological cancers and solid tumors. In addition, with impressive results $n$ the remission rate, relapse or resistance to CAR-T cells may happen (Park et al., 2018). In this review, we discuss the basic structure of CARS in brief. Also, we throw more light on current advances to design safer and more efficient CAR-T cells and look forward to future research possibilities for the treatment of both hematological malignancies and solid tumors.

\section{Chimeric Antigen Receptors (Cars) Structure}

As shown in Figure 1, four major pieces are mainly incorporated in chimeric antigen receptors (CARs). They are theantigen-binding domain, hinge, transmembrane domain and intracellular signaling domain. Each of these compartments has an important specific role. Researchers can optimize the molecular design of CARs by performing different combinations between these domains (Bailey andMaus, 2019).

Antigen-binding domain has anextracellular location for the identification ofthe target antigen and precisely redirects the CAR-T cells as shown in Figure 1. Conventionally, the antigen-binding domain contains two variable domains, the variable heavy chain and the variable light chain of monoclonal antibodies. Both domains are connected by a dynamic and flexible linker to be a single-chainvariable fragment (scFv)(Dwivediet al., 2019). (Gly4 Ser) 3 peptide is considered the typical flexible linker that uses glycine residues to supply more flexibility in addition to serine to supply solubility to a tightly folded scFv for identifying and binding with the target cancerous cell surface antigen (Zhang, 2014). Thereby, the activation of $\mathrm{T}$ cells is depending on CARs with no need for major histocompatibility complex (MHC) as usual. Both MHC-dependent T-cell receptors (TCR) and mimic CARs enable intracellular tumor-associated antigens (TAAs) to be recognized (Rafiqet al., 2017; Inagumaet al., 2014; Oren, et al., 2014 and Zhang, 2014). Moreover, CARs are equipped with scFvs that can connect to soluble ligands including transforming growth factor- $\beta$ (TGF $\beta$ ) in the tumor microenvironment (TME) leading to the transformation of the immunosuppressive signal typically found in solid tumors into a powerful $\mathrm{T}$ cell activator (Chang et al., 2018). 
Construction of single-chain variable fragment $(\mathrm{scFv})$ is commonly from murine or human monoclonal antibodies. CARs also may be constructed to produce nanobodies which main smaller antibodies (Xie et al., 2019). Particularly, CARs engineering may have several effects on CAR-T cell function that may be achieved by using different single-chain variable fragments (scFvs) that target the same protein with the same affinities. Also, choosing the target cancerous cell surface antigen is a crucial factor in identifying the ideal $\mathrm{scFv}$ for optimization binding of CARs with them.

There are also alternative antigen-binding domains for CARs using other molecules than scFv. When cytokines bind to intracellular signaling domains, they are called zetakine CAR-T cells, forexample, those targeting IL13 receptor $\alpha 2$ (IL-13R $\alpha 2$ ) via membrane-bound IL13 linked to the intracellular signaling domain such as 4-1BB and CD3 $\zeta$. It has been extensively tested in many clinical trials. Also, many preclinical and clinical trials studied ligand related CARs along with a wide range of malignancies (Brownet al., 2016). More recently, CAR-T cells with peptide domains developed de novo to respond to several antigens and illustrated preclinical efficacy such as designed ankyrin repetitive proteins (DARPins) targeting HER2 (Hammillet al., 2015 ), or adiponectin peptides derived from human fibronectin targeting EFGR tenth type III domain(Han et al., 2017).

\section{Hinge and Transmembrane Domains:}

The critical role of CARs' hinge and transmembrane domains is to connect the extracellular (antigenic binding domains) portion to the intracellular (signaling domain) portion. The hinge domain also plays an important function in providing the necessary flexibility to deal with steric hindrance and sufficient length to meet the target cancerous cell surface antigens. The composition and length of thehinge region can influence on binding and signaling antigens via the CARs (Jensen \&Riddell, 2015). In addition, the production of cytokines by CAR-T cells and the activation-induced cell death (AICD) are also affected with the hinge and transmembrane domains features. Whereas the hingedomain spacer provides access to proximal antigen epitopes of the CARs membrane, it diminishes the function of CAR-T cells. In designing of hinge domain, amino acid sequences are often used such as CD8, CD28, IgG1, or IgG4 as shown in Figure 1, Although interaction can occur between some of the IgG-derived peptides and Fc $\gamma$ receptors (Fc $\gamma \mathrm{Rs}$ ) contributing to thedepletion of CAR-T cells, thereby clinically decreasing their persistence (Hombach et al., 2010).

The transmembrane is primarily from proteins of type I like CD3 $\zeta, \mathrm{CD} 28, \mathrm{CD} 4$, or CD8 $\alpha$ as shown in Figure (1). The transmembrane domain feature gives stability for the CARs. Using CD28 as a transmembrane domain rather than $\mathrm{CD} 3 \zeta$ provides more stability to CARs for example. On the other hand, using $\mathrm{CD} 3 \zeta$ primarily as a transmembrane domain facilitates thedimerization of CAR and incorporation into endogenous T cells. In particular, it has been found that using CD8 $\alpha$ as a hinge and transmembrane domain releases less IFN $\gamma$ and less TNF. CARs containing CD8 $\alpha$ are less susceptible to activation-induced cell death (AICD) than those containing CD28 as a hinge and transmembrane domain (Alabanza et al.,2017). 


\section{Intracellular Signaling Domains:}

Thefourthportion of the CAR is the intracellular signaling domain. This consists of an activation domain, as seen in Figure (1), and a co-stimulating domain(s). Activation of CAR$\mathrm{T}$ cells is mainly through motifs of activation based on $\mathrm{CD} 3 \zeta$-derived immuno-receptor tyrosine. Such motifs induce signals individually as insufficient to induce successful T-cell responses resulting in $\mathrm{T}$ cells limitation in activity and persistence in vivo (Brockerand Karjalaine, 1995). For optimizing T cell activity and persistence, The co-stimulatory signal is needed. In addition to the activation domains, co-stimulatory domains make CAR-T cells produce IL-2 and can proliferate by repeated antigen exposure (Maher et al., 2002). CD28 and 4-1BB (CD137) are widely used as the domains of co-stimulation. Recently, FDA has approved CAR-T T cell products that containing either CD28 or 4-1BB (CD137). Despite each of these domains has different features, both are associated with high clinical response (Sadelain et al., 2017).

For metabolic properties, CAR-T cells with CD28 domains differentiate into $\mathrm{T}$ effector memory cells that primarily use aerobic glycolysis, but CAR-T cells with 4-1BB differentiate into central memory T (TCM) cells that have enhanced biogenesis of the mitochondria and oxidative metabolism (Kawalekaret al., 2016). CAR-T cells containing other co-stimulatory domains such as MYD88 and CD40 (Mata et al., 2017), OX40 (CD134) (Hombach et al., 2012), inducible T-cell co-stimulator (ICOS)(Guedanet al., 2014), CD27 (Song and Powell, 2012), and killer cell immunoglobulin-like receptor 2DS2 (KIR2DS2; coupled with co-expression of TYRO protein tyrosine kinase-binding protein, also known as DAP12 (Wang et al., 2015) have shown functionality in preclinical trials but have not yet been entered in clinical trials.

Based on the CARs domains, researchers are engineered CAR-T cells in various ways to enhance the safety, efficacy, and durability of CAR-T cell therapies, and the clinical response of CAR-T cells in patients. They also seek to perform wide-ranging CAR-T cell therapy for several malignancies, and boost the manufacturing cycle of CAR-T cells.

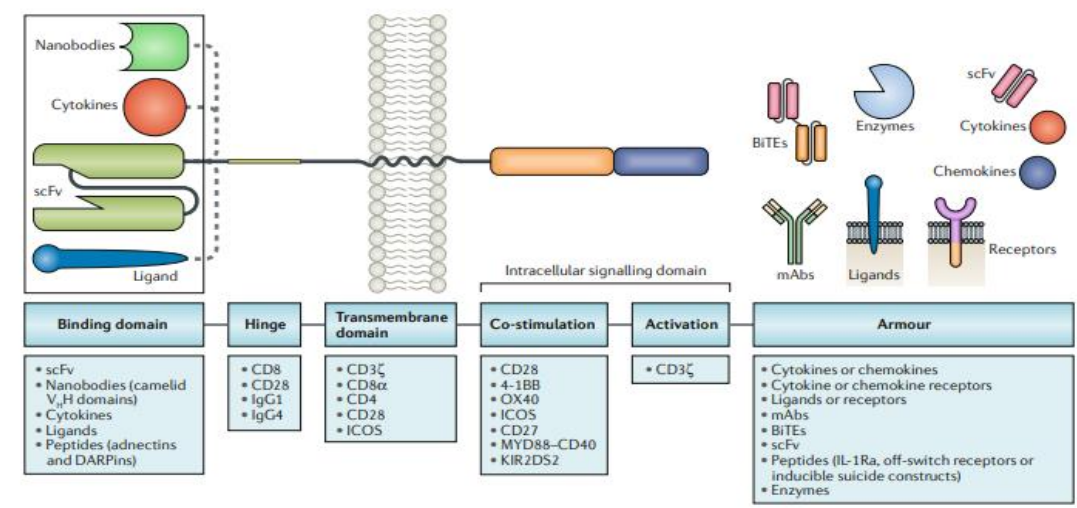

Fig. 1: Chimeric antigen receptors (CARs) design (Rafiq et al., 2019).

\section{CAR-T cell Therapy Design}

CAR-T cell designing is performed based on platforms for gene transfer that have to be safe, effective, and highly stable. The preparation of CAR-T cells is occurred by isolation 
of autologous $\mathrm{T}$ cells using leukapheresis followed by harvesting and genetic modification of the patient's $\mathrm{T}$ cells outside the body, using viral and non-viral transfection methods. The proliferation of modified T-cells happens throughout theculture. Following CAR-T cell development and the passage of quality assurance tests, the patient mostly administrated lympho-depleting chemotherapy before CAR-T cell infusion (Gross et al., 1989).

For the variable monoclonal antibody fragment $(\mathrm{scFv})$, it is derived from mouse monoclonal antibodies (mAbs), humanized Abs, or entirely human Abs. The main role of this variable monoclonal antibody fragment $(\mathrm{scFv})$ is to recognize and bind to tumor-associated antigens (TAAs), which aredemonstrated on the surface of cancerous cells. TAAs may be unprocessed antigens, as well as carbohydrates orglycolipids. Unlike ordinary TCRs, this identification is not depending on thepresentation of antigens via the MHC (Schmidt-Wolf $e t$ al., 1991). For bypassing the restrictions on MHC I and MHC II, CAR-T cells of each CD8 + and CD4 + subset may be recruited for redirecting the identification of the target cell. The mechanism of CAR-T cell therapy for elimination of cancerous cells via redirected CD4 + and $\mathrm{CD} 8+\mathrm{T}$ cells is primarily used in cytolysis as a minimum of two pathways includingperforin and granzyme exocytosis, and to some extent, death receptor signaling via Fas / Fas-ligand (Fas-L) or TNF / TNF-receptor (TNF-R). The IgG1 hinge region is the simplest kind of a spacer. It is sufficient for many scFv-based constructs (Zhanget al., 2015). Since 1989, four generations of CAR-T cells have been developed depending on the intracellular domain structure (Schmidt-Wolf et al., 1991). First-generation CARs include the

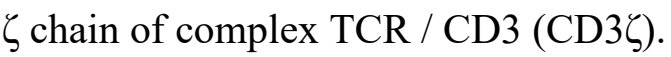

For maximum T-cell activation, the second generation of CARs are characterized by double signals: one activated by antigen recognition and one acts as a co-stimulating molecule such as CD28/B7, the advantages of the second generation of CARs are promoting the development of IL-2 for optimum activation of T-cells and preventing apoptosis (Zhonget al., 2010). The third generation of CARs boosts responses by integrating sequences of co-

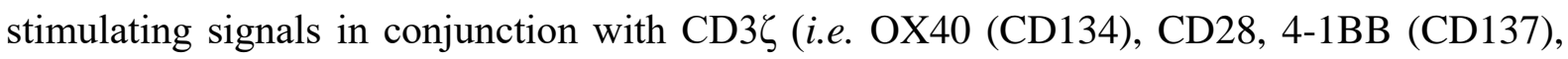
CD27, DAP10 or other molecules) (Priceman et al., 2015). The advantage of using several co-stimulatory signals in combination is to enhance the efficacy of CAR-T cells by increasing cytokine production, T-cell proliferation, and killing within the context of recursive antigen exposure (Sadelain et al., 2010). Clinically, third-generation CARs did not display competitive advantages over patient results as compared with second-generation CARs. This is a tentative finding despite the limited number of cases being investigated. Consequently, there is still a need for more clinical trials to explore the safety and efficacy of thirdgeneration CARs (Yu et al., 2017).

The design of CARs is still in need for more development to reach redirecting CAR Tcells for universal cytokine killing (TRUCK). TRUCK cells promote the release of transgenic products such as IL12 or IFN- $\gamma$. IL12 can stimulate innate immune responses against cancerous cells that have not been identified by CAR T-cells.IFN- $\gamma$ can kill the cancerous cell surface antigens independently via the IFN- $\gamma$ R that is located in the tumor stroma as seen in Figure (2) (Miliotouand Papadopoulou, 2018). Biphasic CAR, also known as tandem CAR (TanCAR), is a single transgenic receptor thatcan recognize two specific antigens. It offers synergistic tumor cell destruction and enhanced effect. The recognition domains of the two distinct antigens are tandems and separated by a flexible hinge. This architecture is for 
preventing the escape of cancerous cells and the loss of antigens. In case of one target antigen is down-regulated or mutated; TanCAR remains successfully acting and maintains the CAR-T cells' cytolytic activity (Grada et al., 2013). Kloss et al.(2013) and Wilkie et al.(2012) developed dual specific CARs to enhance the cancer specificity. By the co-expression of two distinct CARs within the same CAR-T cell population, complementary signals are provided as each recognizes a different cancerous cell surface antigen. This concept may be used as "tumor barcoding" and destroys only the two positive cancerous antigen cells. These CAR-T

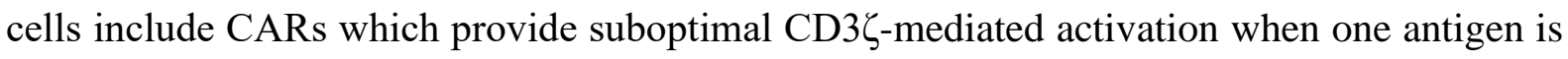
binding and a chimeric co-stimulatory receptor contains only CD28 and 4-1BB which recognizes a second antigen. This strategy provides more precision for CAR-T cells, avoids off-target effects, and guarantees maximum activation of $\mathrm{T}$ cells as soon as they reach dual CAR targets. Double universal CARs program is another possible solution. This system contains CARs with scFv for avidin (Urbanska et al., 2012) or scFv for anti-fluorescein isothiocyanate (FITC)(Tamada et al., 2012).

CAR-T cells are capable to identify the same antigen on both tumor and off-target tissues. They can be restricted only to cancerous cells by using an antigen-specific inhibitory CAR (iCAR). This is inserted into the $\mathrm{T}$ cells to protect healthy tissues from off-target influences. Therefore, these CAR-T cells will selectively restrict cytokine secretion, cytotoxicity, and proliferation (Junejaet al., 2017; .Dai et al., 2016 and Fedorovet al., 2013). The dual action of this form of CAR-T cell therapy and inhibitor checkpoint blocking through the use of antagonistic antibodies against the negative CTLA-4 and PD1/PD1-L regulators has huge potential as the main blockage of the immunosuppressive pathway PD-1 significantly improved the role of anti-HER2 CAR-T cells leading to cancer eradication in immune-competent HER2 transgenic mice (John et al., 2013).

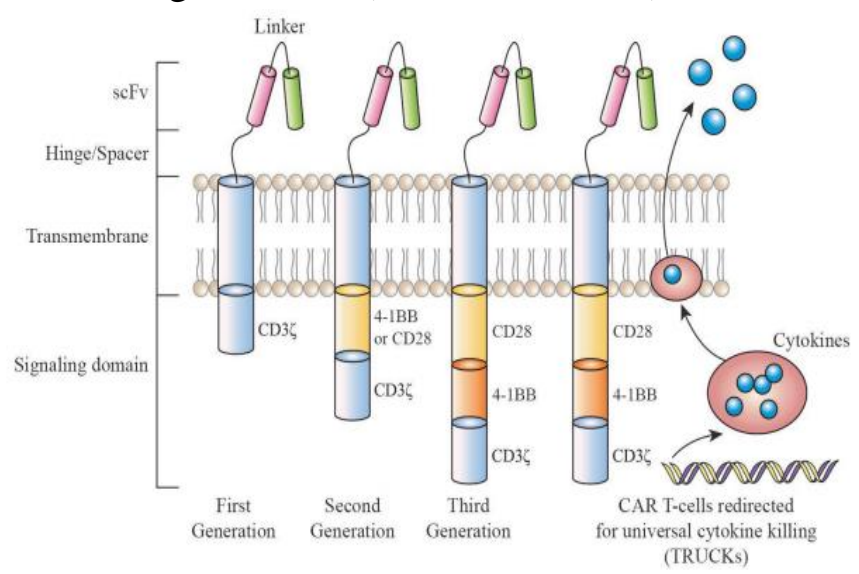

Fig. 2: CAR-T cell generations, first-generation CARs signaled only via the CD3 chain, secondgeneration CARs additionally integrate a signaling domain from a co-stimulating molecule, for example, CD28 or 4-1BB and third-generation CARs have two co-stimulating signaling domains in combination with the CD3 chain (Miliotou and Papadopoulou, 2018).

\section{Genetic Engineering Methods Used in The Development Of CAR-T Cells}

From the1970s up till now, CAR-T cell genetic engineering has been continuously modifying from basic physical-chemical laboratory approaches to viral and non-viral techniques of transfection to achieve high transgenic expression with less harmful or 
oncogenic adverse effects. CAR-T cells basic architecture can be performed using several techniques of gene transfer relevant in clinical practice. It includes methods for viral transduction, transposons and mRNA transfection, in addition to nanoparticles, liposomes, electroporation or the use of CRISPR / Cas9. This review describes the benefits and disadvantages of these approaches.

\section{Viral Transduction:}

Actually, viral transductions are the most commonlyfavored approach for engineering CAR-T cells. It is performed by using retroviruses (lentivirus and $\ddot{y}$-retrovirus), adenoviruses and adeno-associated viruses. By the way, Retroviridae family viral vectors are now the most widely used vectors for applications in gene therapy. The viral gene transfer vectors are mainly characterized by their relatively simple development and their capabilities to incorporate the genetic material stably into the host genome. Viral vector systems must fail to replicate, with no or minimal genotoxicity or immunogenicity to meet clinical safety levels. Because of retroviruses have two basic features, they are especially suitable for serving as gene transfer vectors. Firstly, much of the viral genome can be replaced with a transgene(s) of interest. Secondary, the viral genome is continuously incorporated into the transduction genome of host cells. Moloney murine leukemia virus (Mo-MLV) as one of the $\ddot{y}-$ retroviruses was the first to be successfully designed to act as advanced gene transfer packaging systems. The lentiviral vectors are also commonly used. They are based on the human immunodeficiency virus (HIV). The critical genes gag, polandenv (plus rev for lentivirus) are extracted from the viral backbone to become a CAR vector, then they are produced for viral development in trans, in helper plasmids. CAR transgene is used instead of certain viral genes. To achieve a stable virus-producing line of cells for large-scale development, a packaging cell line is transfected with the CAR transgene vector plus the helper plasmids (with gag, polandenv genes). For genomic integration, stimulated T-cells are inoculated with OKT3/CD28 beads, with retroviral particles. The virion core is released into the cytosol, and transported through the microtubules to reach the nucleus, according to the fusion of viral and host membrane. This method allows T-cell production, expressing high CAR levels. Transduction efficiency of the CAR transgene across viral vectors for retroviruses reaches up to sixty-eight percent, depending on the multiplicity of the infection (Piscopo et al., 2018 and Tumaini et al., 2013).

The long terminal repeats (LTRs) are called the gene expression viral control core that acts as stimulator, promoter, initiation of transcription (capping), terminator of transcription, and signal of polyadenylation. Even though 3'LTR and 5'LTR have the same sequence, 3'LTR typically works in termination of transcription and polyadenylation but not as a promoter. The basis for one type of retroviral oncogenesis is focused on 5"LTR disruption and 3'LTR conversion to a promoter. Nowadays, the safety profile of these vectors is high, resulting from the limited deletion of the 3'LTR U3 region as well as the use of Cytomegalovirus (CMV) promoter to substitute the 5'LTR U3 region for starting the transcription. This technique greatly decreases the virus' transcriptional activity from the LTR. However, there is still a chance of insertional oncogenesis within the genome at random sites, and potential immunemediated toxicity, triggered by long-term persistence and engineered $\mathrm{T}$ cell activity. There are also limits on the size and number of genes that can be packaged and, in such vectors, and 
under-efficacy. In particular, heterogeneous copy numbers can arise to T-cell populations with wildly variable cytotoxic abilities due to varying rates of cell surface expression (Cullenet al., 1984). There are other problems related to the processing of viral carriers that have huge production expenditures. Although the size of viral development was adequate for only clinical trials Phase I / II, a major obstacle would be cost-effective execution of virusmediated CAR fast and comprehensive clinical translation treatment.

\section{Transposons:}

Transposons are described as genetically dual moving pieces. One of them consists of one CAR plasmid (transposon) and another one is transposase plasmid. Such dual component vector systems (sleeping beauty (Jinet al., 2011) and piggyback (Manuri et al., 2010)) can result in stable integration of a transgene. The basic mechanism of this system includes the transposase, which operates on inverted terminal repeats (ITRs) flanking the CAR sequence, Thus, the terminal-repeat (TA) dinucleotide sequence in the target cell genome is excised and subsequently inserted. DNA plasmids that hold both the CAR (as the transposon) and the transposase are electroporated into T-cells. The CAR protein is expressed on $\mathrm{T}$ cell surface following transposition and stable genomic integration. Transposonmediated CAR therapy is considerably more reliable, less toxic when transfected into human cells, with reduced production costs and faster preparation compared to traditional plasmids. Monjeziet al. (2017) designed CD19 CAR-T cell therapy using non-viral Sleeping Beauty Stable conversion of CAR genes from supercoiled, minimal DNA vectors called Minicircles (MCs). The integrants of MC-derived CAR transposons were noticed into genomic safe harbor loci, reducing the risk for insertional mutagenesis and genotoxicity in comparison with LV-derived CAR, incorporating highly expressed and cancer-related genes. The piggyback mechanism tends to have a higher gene transfer efficiency comparing with sleeping beauty. It has close proto-oncogenes and without even proto-oncogene incorporation. It also generates usable CAR-T cells, though the clinic has not yet tested them (Oldham \&and Medin, 2017).

\section{CRISPR/Cas9:}

The scientific community's attention was shifted to methods of genetic "editing" at the start of 2000 by innovating Zinc finger (ZFNs) and nucleoside transcription activator-like effector nucleases (TALENs). ZFNs and TALENs are chimerical, adapted restriction enzymes engineered for different genetic sites, and accustomed sites as safe havens. This technology has been performed to date in CAR therapy to knock out the endogenous TCR receptor in allogeneic $\mathrm{T}$ cells, which may prevent undesirable graft-versus-host disease (GvHD), although the CAR transgene was virally transfected (Cellectis-UCART19) (Cellectis, 2027 and Qasimet al., 2017). In addition, genome editing strategies may be implemented to avoid or postpone the patient's immune system's rejection of CAR-T cell therapy by suppressing or reducing the expression of histocompatibility antigens on donor $\mathrm{T}$ cells. CRISPR / Cas9 technology was considered the breakthrough in the genetic "editing" process. The Type II CRISPR Cas9 protein is primarily used by a short guide to RNA (gRNA), where it functions as an endonuclease, to attack any region in the genome. The 
endonuclease may be transmitted by liposome-mediated transfection, electroporation, chemical transduction or as part of a viral genome (DeWitt et al., 2017) in the form of Cas9 protein / gRNA ribonucleoprotein (RNP) (Liang et al., 2015); and in the form of a plasmid that is guided by either U6 and H1 promoters to transcribe mammalian cells after transfection. In the following step a plasmid-shaped donor template is applied to fuse the desired transgene via homology-directed repair (HDR). In addition, a non-viral alternative approach is applied through nanomaterials. One such technique relies on the biotinstreptavidi and the transportation and binding of human cells from the donor to the Cas9 transformed templates, the gene transfer levels is more than traditional methods by up to five times (Piscopo et al., 2018).

The use of CRISPR technology in the development of CAR T-cells leads to high standard of uniformity and impressive output of survival rate among mouse models. More precisely, the introduction of the CAR sequence into the endogenous T-cell receptor locus "alpha constant"- TRAC strengthened the CAR T-cell cytotoxicity (MacLeod et al., 2017). The efficacy of gene editing for CAR knocking still appears poor, with success rates up to $20 \%$ and there are still some limitations of the off-target mutagenesis (Ren \& Zhao, 2017). During the first clinical trial of CRISPR / Cas9, PD-1 and endogenous TCR were knocked out by CRISPR / Cas9 in T cells of patients with lung cancer, while CAR or TCR were not incorporated into T cells in that trial (Cyranoski, 2016). PD1 knock out autologous T cells for prostate (NCT02867345), bladder cancer (NCT02863913), and renal cell carcinoma (NCT028) for specific purposes, bladder cancer (NCT02863913) and renal cell carcinoma (NCT02867332) are still under progress. The main aim is to eradicate unpredictable incorporation of viral delivery systems as well as management of integration with CARs. It is uncertain if the elimination of such inhibitory signals from the $\mathrm{T}$ cells results in excessive cell proliferation or extensive autoimmunity (Ren \& Zhao, 2017).

\section{Non-viral Transfer Methods:}

Genetic modification of T cells using non-viral plasmid DNA or mRNA transfer is preferred because of their low immunogenicity and low chance of mutagenesis. Identification of using mRNA for gene therapy applications first using liposome-mediated transfection was discovered by Malone et al. in 1989 (Curran et al., 2015). While identification of the TCR genes transfer through the electroporation of mRNA into primary $\mathrm{T}$ cells was performed by Zhao et al., 2006. Although the discovery of a therapeutic approach using mRNA raised many questions and has major challenges due to its features along with sensitivity and destruction susceptibility, instability, negative load, and insufficient translation in the cells of the host and immuno-stimulative effects. By understanding of the relationship between mRNA structure and stability, besides the discovery of various techniques for chemical modification, these issues were circumvented. The mRNA's numerous structural modifications are the inclusion of analogs of the anti-reverse cap (ARCAs) and polyadenylate tail. The add value of these techniques is improving translational performance and stabilities of mRNA. Having the poly (A) tail more than 100 residues is preferable. The replacement of elements of adenylate-uridylate rice (AREs) with a more stable $\beta$-globin gene 5'UTR (untranslated region) and 3'UTR is another modification. The well known AREs are the main 
signs of degradation of mRNA in many eukaryotic mRNAs in the 3'UTRs. ARE-containing mRNAs result in reduced stability, may be due to the removal of the poly (A) tail. The stability can be increased by substitution of AREs with the 3'UTR of a more stable mRNA, such as the $\beta$-globin mRNA. These techniques increase the stability of mRNA and allow the expression of it for longer periods. The transmission of mRNA performs cytoplasmic expression mechanism; it is not in need to reach the nucleus to perform its role (Yu et al., 2017).

IVT- RADIVT- mRNA is formulated with essential modifications that enhance stability. Consequently, improving the modalities of delivery of mRNAis a critical issue for its implementation as a therapeutic tool. By cell membrane disruption, IVT-mRNA can be transmitted, such as electroporation and gene gun, or by endocytosis of different nanoparticles (Moffett et al., 2017), For example, viromers complexes of protamine-mRNA, lipid nanoparticles, polymeric nanoparticles, and polymer hybrid nanoparticles and gold nanoparticles (Islam etal., 2015). Lipofectamine is widely used as a cationic carrier to inject IVT-mRNA into cells. Lipofectamine consists of cationic lipids forming liposomes with positively charged surfaces and promoting the entry of mRNA by endocytosis, into the eukaryotic cell as the following, positively charged liposomes interlink with nucleic acid backbone phosphate groups and form a complex that interacts with the negative charged cytoplasmic membrane, thereby enabling the complex to combine with it. The complex accumulates intracellularly, escapes from the endosome and enters the cytoplasm to be expressed by the genetic material (Cardarelli et al., 2016). Electroporation is thought one of the most promising approaches for incorporating $\mathrm{T}$ cells into the CAR IVT-mRNA model. It has been stated that IVT mRNAtransfection via electroporation was reliable very well under certain conditions, with apoptosis associated with low electroporation (Zhao et al., 2006). Many trials confirmed that the positive tumor toxicity of T-cells and NK electroporated by IVT-mRNA CAR in pre-clinical models (Glienke et al., 2015).

The mRNA mediated transfection systems allow quicker changes in the design of CARs and are safer compared to long-term, integrated, viral expressions. Given their short lifetime and transient expression, clinical extra protection is achieved by the employment of IVT-mRNA transfection technology. In addition, by the time IVT-mRNA degradation ensures the patient's complete removal of the CAR with no need for it (Angel and Yanik, 2010). Furthermore, IVT-mRNA mediated transfection systems are easier to transfer into GMP platform with dramatically economic costs and less complicated release tests (Barrett $e t$ al., 2013). Besides, patients require only a few repeated infusions (3-9 infusions) of CAR-T cells to appear a long-lasting response (Beatty et al., 2014). CARs transfected to modified T cells using mRNA were extensively evaluated in the University of Pennsylvania clinical trials (Philadelphia, PA; NCT02624258, NCT01837602, NCT02277522, NCT02623582). In fact, a great effort was done to address solid tumors with CAR T-cells modified by electroporated IVT-mRNA (Brown et al., 2015). Electroporation may lead to cell death, particularly when electrical fields in a process known as irreversible electroporation result in permanent membrane permeation and the consequent loss of cell homeostasis. Using surface plate electrodes, when the electroporation field is applied to the skin the main "potential" decrease occurs along the skin rather than along the subcutaneous tissues of the target. Skin swelling is 
a typical consequence of electroporation in vivo. A lot of protocols for electroporation are aiming to penetrate the plasma membranes only. A further phase is needed for the nucleus electroporation using higher voltage and less pulse length (nucleoporation). In addition to, while the electroporation principle is applicable to all types of cells, its usefulness is based on the cells' electrical characteristics. The smaller in size, the cells need to reach a higher area. Cells that have less conductive elements such as fat cells are less sensitive. Therefore, thresholds vary for specific cells in a heterogeneous tissue (Bolhassaniet al., 2014). The use of IVT-mRNA rather than MC- or plasmid-encoded transposase and CAR gene is preferred because of the lack of deliberate incorporation into the host genome. However, the key disadvantages of these systems are the long ex vivo culture time needed to develop therapeutic doses of gene modified T-cells and the serious cell damage that can follow the plasmid DNA electroporation.

\section{The Opportunities and Other Research Possibilities}

\section{In hematological malignancies:}

Although the most pronounced clinical efficacy of CAR-T cell therapy has been observed up to now in hematological malignancies, especially CD19 + B cell lymphoma or ALL, there is still scope for research on antigen escape and restricted persistence of CAR-T cells among patients, resulting in reduced response durability and consequently the effectiveness of CAR-T cell therapy in these diseases. Several approaches are being developed to overcome these limitations and to extend use of CAR-T cells in patients with hematological malignancies with CD19.

\section{For overcoming antigen escape:}

During the primary response of CAR-T cells, antigen escape happens at high levels. A small proportion (7-25 percent) of patients administered with CAR-T cells (Majzner andMackall, 2018) demonstrated complete or partial loss of target antigen expression by the cancerous cells. While CAR-T cells target multiple antigens perform different combinatorial strategies to counter antigen escape. Clinical management of various patients using CAR -T cell products was more successful when identifying alternative antigens (Pan et al., 2019). The creation of a single CAR-T cell product that has specificity for multiple targets is a promising approach. Multi-target CAR-T cell therapies can be prepared by mixing different CAR-T cell product lines, each targeting single antigen before infusion or by transducing modified $\mathrm{T}$ cells with multiple CAR constructs. On the other hand, dual different CAR-T cells can be equipped with two or more distinct binding domains as a single CAR molecule. For example, in patients with B-cell malignancies CD19/CD20 or CD19/CD22 CAR-T cells have shown impressive therapeutic responses (Mahadeo et al., 2019 and Shah et al., 2019).

The further modification of CAR-T cells to secrete bi-specific $\mathrm{T}$ cell engagers (BiTEs) is another multi-targeted technique. BiTEs consisting of two scFvs, one specific to CD3 and the other specific to a TAA, attached by a flexible linker; these agents can therefore physically bind a T cell to a cancer cell (Kantarjian et al., 2017) BiTE secreting CAR-T cells have been successful in tackling antigen expression heterogeneity and also antigen escape in 
preclinical trials of both leukemia and solid tumors (Choi et al., 2019), as shown in Figure $3(\mathrm{a}-\mathrm{c})$.
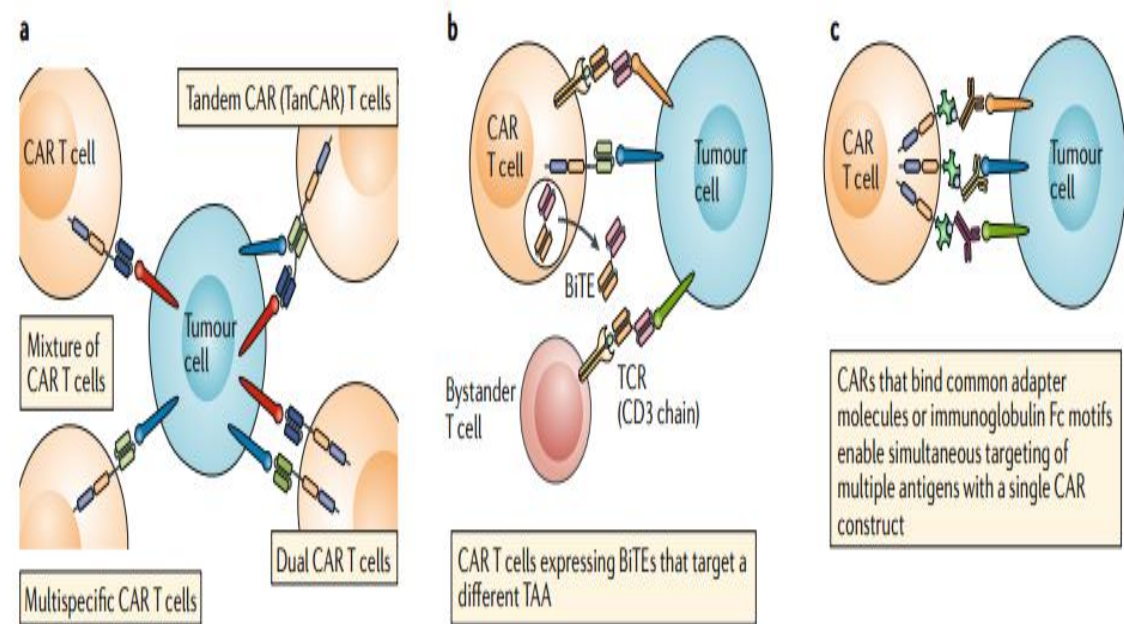

Fig. 3: Targeting of multiple antigens to overcome antigen escape or heterogeneity (Rafiq et al. 2019).

\section{Increasing CAR-T cell persistence:}

The persistence of CAR-T cells in patients can be expanded by one promising strategy. It is predicated on the use of $\mathrm{T}$ cell populations with higher percentages of less differentiated $\mathrm{T}$ cell subsets that have a greater proliferative capacity, such as naive $\mathrm{T}$ cells, stem cell memory T (TSCM) cells and central memory T (TCM) cells(Busch et al.,2016)(Fig. 4). comparing to traditional CAR-T cell products, preclinical trials using CAR-T cells generated from preselected naive $\mathrm{T}$ cell populations or manufactured in the presence of kinase inhibitors to generate CAR-T cells with a less- differentiated phenotype have shown superior proliferation and anti-cancer activity (Morgan andSchambach, 2018and Petersen et al., 2018).

As co- stimulation is a critical component of effective CAR- T cell while excessive co-stimulation might decrease the persistence of CAR $\mathrm{T}$ cells in vivo. Therefore, the developed strategies are addressing this issue involving altering the co-stimulatory domain of the CAR to decrease the intensity of the signal (Feuchtet al., 2019). Also, the co-stimulatory signal can be modulated via co-expression of ligands for auto- stimulation and transstimulation of CAR T cells. For example, co-expression of 4-1BBL on CAR-T cells with CD28 co- stimulatory domains results in CAR- $T$ cells with a longer duration of persistence, decreased expression of exhaustion markers and a high $\mathrm{CD}^{+}$to $\mathrm{CD} 4^{+} \mathrm{T}$ cell ratio compared with CAR-T cells expressing only CD28-based or 4-1BBL - based CARs. Such CAR-T cells, expressing 4-1BBL, are currently conducted in clinical trials for relapsed CD19+ hematological malignancies (Park et al., 2018) as shown in Figure 4 (a \& b). 


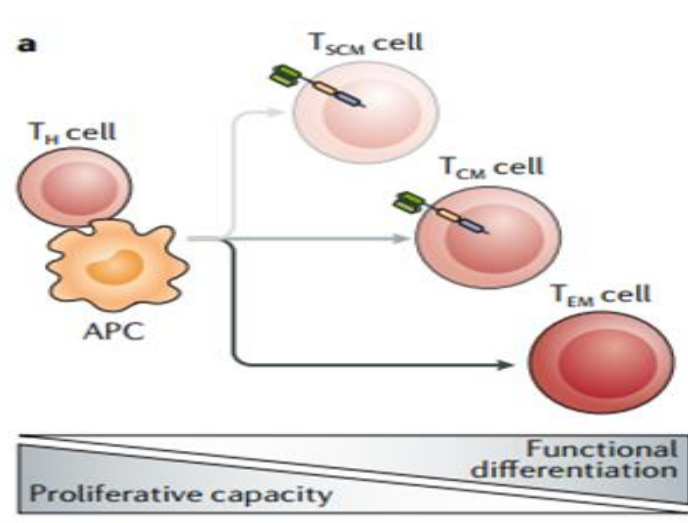

Use of less-differentiated T cell subsets with greater proliferative potential

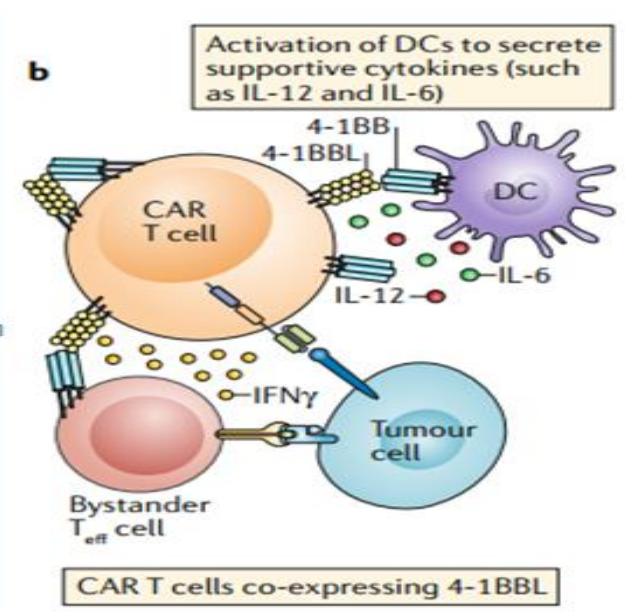

CAR T cells co-expressing 4-1BBL

Fig.(4): Enhancing in vivo CAR-T cells persistence (Rafiq et al., 2019).

An alternative strategy for generating T-cell responses against multiple TAAs is the production of CAR-T cells that can enhance endogenous immune response. These agents are referred to as armored CAR-T cells, and are co-modified with immunomodulatory agents which involve and modulate the immune cells of another host. CAR-T cells which have been updated to express the CD40 ligand $(\mathrm{CD} 40 \mathrm{~L})$ proinflammatory molecule represent a good example. In addition to enhanced intrinsic functionality due to co-stimulation with CD40L, these cells are supportive of triggering professional antigen presenting cells and enhancing the immunogenicity of cancer cells through CD40 involvement, thus encouraging the detection and removal of tumor cells even by endogenous unmodified T cells (Kuhn et al., 2019) as shown in Figure 5.

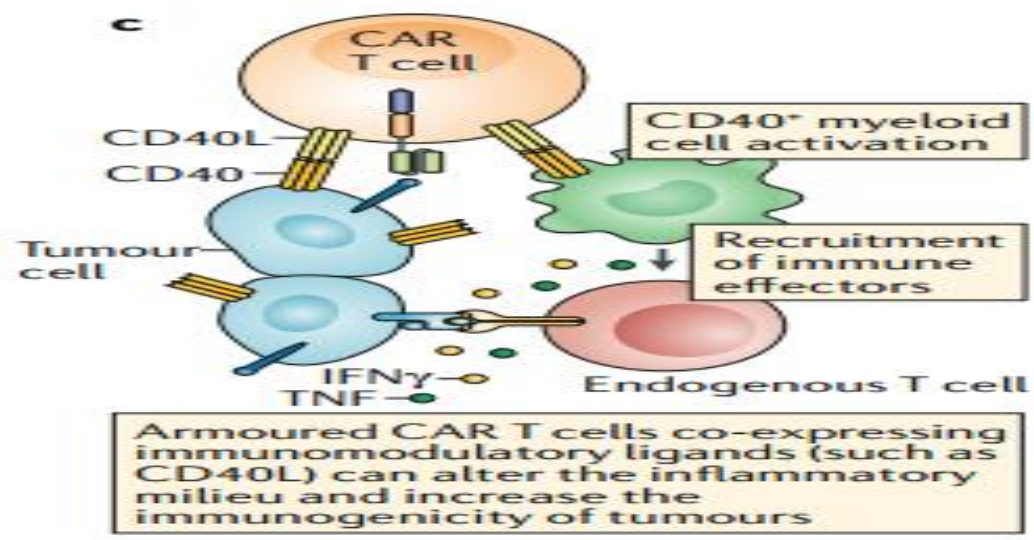

Fig. 5: Enhancement of endogenous immune response (Rafiq et al., 2019).

\section{In Solid Tumors}

In spite of treatment of hematological malignancies with CAR-T cell therapy has been a reported efficacy, there has been no equivalent efficacy with solid tumors so far (Centers for Disease Control and Prevention, 2019). This is regarding to multiple factors, including the lack of proper tumor-specific antigens or TAAs with expression profiles that are likely to 
be associated with on target, off tumor Toxicity is a huge hindrance to the efficacy of CAR-T cells on solid malignant tumors. The numerous lack of efficacy found with different CAR-T cell therapies targeting various solid tumor antigens that means there are general limitations for any CAR-T cells equipped. Solid tumor has complicated architecture and cellular nature that affects the biology of the tumor itself and its response to therapies) (Junttilaand de Sauvage, 2013). Solid tumors found in tissues have lower endogenous T cells than lymphoid tissues and lower rates of homeostatic cytokines and other $\mathrm{T}$ cell contributing factors usually derived from bone marrow and stroma lymph node. The solid tumor stroma structure can present a physical barrier to the penetration of CAR-T cells. Additionally, suppressive immune cells, such as regulatory $\mathrm{T}$ (Treg) cells and myeloid-derived suppressor cells, and immunosuppressive ligands, such as programmed cell death-ligand 1 (PD-L1), present in the tumor microenvironment, may all significantly reduce intrinsic anti-tumor immune responses and also CAR-T cell responses.

\section{Overcoming antigen heterogeneity:}

To overcome the antigen heterogeneity of the solid tumors various approaches have been developed. Some of which mimic the aforementioned strategies in hematological malignancies to prevent the escape of antigen. Anti-EGFR BiTEs have been demonstrated increase the effectiveness of anti-EGFRvIII CAR-T cells among glioblastoma mouse models and even anti-folate receptor $\alpha$ CAR-T cells in preclinical ovarian models, colon or pancreatic cancer (Wing et al., 2018). By discovery of uniform CARs for which the adapter elements used as ligands, targeting of various antigens with a single population of CAR-T cells achieved, as shown in Figure 3c. For example, avidin-linked CARs, which in combination with biotinylated antibodies often called biotin-binding immune receptors, may be used not only to regulate CAR-T cell activity similar to a safety switch but also to target different antigens, whether sequentially, or at the same time (Lohmuelleret al., 2017). CARs with scFvs capable of detecting fluorescein fluorophore isothiocyanate combined with TAA binding molecules to target numerous antigens concurrently were used in other strategies (Lee et al., 2019). CARs that contain FcÿRs as the antigen-binding domain allow the use of therapeutic TAA-binding antibodies to target several antigens with a single CAR molecule (Kudo et al.,2014) Leucine zipper motifs are used in the SUPRA (split, universal and programmable) CAR system (Cho et al., 2018)to align CARs (zipCAR) with free scFvs (zipFv), again allowing the concurrent targeting of multiple antigens as well as the incorporation of multiple antigen logic gates and the amplification of CAR T cell activation (the CAR T cells are only active when zipFv is present). These and other technologies could go ahead. These and other approaches may provide a way for effective targeting of patients with heterogeneous solid tumors and reducing off-tumor toxicity.

\section{Increasing CAR-T cell trafficking:}

Several methods were created to enhance CAR-T cell traffic to solid tumors. In vivo, CAR-T cells were directly injected into tumors at distinct anatomical sites such as brain (Brown et al., 2016), breast (chou et al., 2017), pleura (Beatty et al., 2014), and liver 
(Hardaway et al., 2018) to prevent blood mobilization to induce observed effects. Additionally, local infusion of CAR-T cells can also restrict off-tumor, on target toxicities (Sridhar \& Petrocca, 2017) This approach is limited only to single tumor lesions or oligometastatic disease and may be more resource-intensive than more established local therapies, but CAR-T cells delivered locally have the potential to expand and traffic to other tumor sites reinforcing tumor response by endogenous immune cells. Two patients received infusions of $\mathrm{T}$ cells transduced with mRNA encoding an anti-mesothelin CAR, one of which provided evidence of an elicited humoral antitumor response including several additional antigens in both the intravenous and regional infusions (Beatty et al.,2014). The same findings were not yet commonly reported in trials, including the delivery of CAR-T cells intra-tumor. This finding demonstrates the potential for using targeted delivery to activate systemic immune responses to the anti-tumor. Indeed, localized therapies are not appropriate to be used in many metastatic solid tumors and thus efforts are under way to prepare CAR-T cells have an inherent capacity to transport to tumor sites.

The transportation of immune cells is mediated by chemokines (Nagarsheth et al., 2017). Chemokine signal modulation has been found to enhance transportation and localization of $\mathrm{T}$ cells in solid tumors. In a preclinical research, CAR-T cells expressing the macrophage colony-stimulating factor 1 receptor (CSF-1R) were receptive to CSF-1 (a monocyte-recruiting chemokine enriched in many solid tumors), which reinforced the proliferative effects of CAR signaling without sacrificing cytotoxicity and did not provoke trans-differentiation into the myeloid lineage. Encouraged expression of the CC-chemokine receptor 4 (CCR4), usually expressed on T-helper cells and Treg cells, and activated by CCchemokine ligand 17 (CCL17) and CCL22 (secreted by Hodgkin lymphoma Reed Sternberg cells), enhanced both CAR-T cell migration to tumors and anti-tumor activity in a Hodgkin lymphoma mouse xenograft model ${ }^{\mathrm{Di}}$ (Stasiet al., 2009 and Lo et al., 2008) In conjunction, encouraged expression of CCR2b, which is the receptor for CCL2, a chemokine overexpressed in different sorts of solid tumors, boosted the infiltration of anti-GD2 CAR-T cells into neuroblastoma xenograft tumors by more than tenfold and anti-mesothelin CAR-T cell infiltration into mesothelioma xenografts by more than twelvefold, with corresponding increases in anti-tumor activity (Moon et al., 2011).

\section{Overcoming micro-environment physical barriers:}

Development of different approaches in order to heighten the potential of CAR-T cells to resolve physical barriers reaching the solid tumor microenvironment (TME) and to address inhibitory stromal architectures. The expression of protease fibroblast activation protein (FAP) by various tumor-associated stromal fibroblasts that plays a significant role in tumor extracellular matrix (ECM) remodeling, providing this prolyl endopeptidase a desirable target for increasing the penetration of immune cells into solid tumors. Various findings in other attempts to treat FAP expressing stromal cells with CAR-T cells. One trial, due to its effect on FAP+stromal cells in the bone marrow, FAP targeted CAR-T cells led to cachexia and bone toxicity while having restricted effect on the maturation of various tumors in immuno-competent mice (Tran et al., 2013). In another immuno-competent mice trial, FAP targeted CAR-T cells with a specific anti-FAP scFv reduced tumor growth when used in 
conjunction with a vaccine and without significant toxicity (Wang et al., 2014). Hence the effectiveness and toxicity profile of CAR-T cells targeted by FAP still needs deeper studies. Another technique to promote the penetration of these cells into solid tumors is to develop CAR-T cells secreting ECM modifying enzymes. Anti-GD2 CAR-T cells engineered to dissolve proteoglycans of heparin sulfate in the ECM via expression of heparinase had an enhanced capacity to infiltrate xenograft tumors in mouse models and sustained survival compared to CAR-T cells lacking heparinase expression (Caruana et al., 2015). Other enzymes degrading the ECM are also being monitored for their function in CAR-T cells (Mardomi and Abediankenari, 2018). Although the application of the pegylated form of the ECM degrading enzyme hyaluronidase (PEGPH20) to chemotherapy decreased the overall survival of pancreatic adenocarcinoma patients in one trial (Ramanathanet al., 2019), this finding was not seen in another using a different chemotherapy regimen (Hingorani et al., 2018). Find it interesting that patients receiving PEGPH20 in these studies needed low molecular weight heparin supplementation to accommodate for an increased risk of thromboembolic events, raising the possibility that T cells modified to change the ECM may also increase the risk of these occurrences. Thus, while ECM modification for solid tumors is an exciting frontier in CAR-T cell therapy, caution is needed because of the confusing and unexpected outcomes of ECM modifying enzymes at present.

\section{Overcoming direct $\mathbf{T}$ cell inhibitory signals:}

Resolving the direct inhibitory signals from $\mathrm{T}$ cells present in the TME is an important issue for CAR T cells. Although multiple inhibitory signals may be present in the TME, PD1, which is an immune checkpoint receptor expressed on activated $\mathrm{T}$ cells, is the best characterized path. When it is bound by PD-L1, which can be expressed by tumor cells and other types of cells, $\mathrm{T}$ cells are induced to adopt an exhausted ineffective phenotype. Consequently, suppression of the PD-1 pathway in patients with certain solid tumors forms maybe resulted in a dramatic therapeutic benefit (Postowet al., 2015). It has been noticed that PD-1 expression and other inhibitory receptors is a mechanism by which CAR-T cell impairment occurs (Moonet al., 2014). On the other hand, numerous studies have shown an increase in the effectiveness of CAR-T cells with co-administration of antibodies inhaling that inhibits the PD-1 pathway in preclinical trials (Yoon et al.,2018) and subgroups of ALL patients (Li et al.,2018) or diffuse large B cell lymphoma (Chong et al., 2017); Dramatic antitumor responses have also been observed in patients who received anti-PD-1 antibodies after CAR-T cell therapy mediated by mesotheline (Adusumilli et al., 2018). Other effective techniques for genetically engineering disruption of the PD-1 pathway into CAR-T cells themselves have been established. For example, CAR-T cells with a truncated dominant negative PD-1 receptor lacking intracellular signaling domains that are capable of binding to PD-L1, but are unable to convey inhibitory signals, withstand PD-L1-induced exhaustion and prolonged survival of pleural mesotheliomas in mice carrying xenograft compared to CAR-T cells which lack this decoy receptor (Cherkasskyet al., 2016).

Based on PD-1 switch receptors, there is another approach where PD-1's extracellular domain is fused to the CD28 transmembrane and intracellular signaling domain. Eventually, in 
addition to functioning as dominant negative inhibitors of immunosuppressive signaling by endogenous PD-1 molecules in $\mathrm{T}$ cell, these switch receptors transmit an activating costimulating signal when stimulated by PD-L1 (Kobold et al.,2015) or in engineered CAR-T cells (Liu et al.,2016) that used for adoptive cell therapy, thereby improving efficacy in several preclinical trials. Also, researchers have engineered CAR-T cells that secrete antagonistic IgG1 antibodies that can respond to PD-L1 on tumor cells and antigen presenting cells to prevent the exhaustion of T cell, and recruit NK cells that can mediate antibodydependent cell cytotoxicity to solid tumors, as shown in a renal cell carcinoma xenograft model (Suarez et al., 2016). Likewise, CAR-T cells engineered to secrete antagonistic antiPD-1 scFvs have enhanced functionality and sustained survival of PD-L1 + haematological or solid cancers in xenograft and immunocompetent syngeneic mouse models (Rafiq et al.,2018). These scFvs can also connect to endogenous $\mathrm{T}$ cells in the TME prohibiting their suppression ( $\mathrm{Li}$ et al., 2017) indicating the opportunity for using CAR-T cell therapies with immune checkpoint inhibition as both technologies enhance CAR-T cell function and also endogenous $\mathrm{T}$ cells. In addition to the physical antagonism of the PD-1-PD- L1 pathway, gene silencing techniques concerning short hairpin RNAs (Cherkassky et al., 2016) or CRISPR - Cas9 (Ruppet al., 2017) were used to delete the PD-1 (PD1) gene encoding in CAR-T cells. Specifically, while there is a theoretical role of PD-1 in T cell activation (Wei et al., 2019; Simon\& Labarriere, 2017), more research of the influence of these strategies on the function of CAR-T cells is still required. Short hairpin RNA mediated down regulation of the CTLA-4 inhibitory receptor also found to boost the activity of first-generation, CD3 $\zeta$ signals of CAR-T cells but had no biological role on second-generation, CD28-CD3ל- signals of CAR-T cells (Condomines et al., 2015).

CAR-T cells have also been designed to counteract the action of adenosine in TME, which can trigger adenosine receptor $\mathrm{A} 2 \mathrm{~A}$ and eventually inhibit $\mathrm{T}$ cell activity via expression of a small peptide disrupter of the interaction between A2A-activated kinases PKA and ezrin (Newick et al., 2016), siRNA silencing of A2A (Beavis et al., 2017), or with nanoparticles to deliver a small molecule A2A antagonist (Siriwonetal., 2018). In particular, dominant negative receptors have been formed that serve as a sink for immunosuppressive cytokines, including TGF $\beta$, and hence boost the role of CAR-T cells in TME (Kloss et al.,2018). CAR-T cells were also formed to express decoy or transfer cytokine receptors that functionally transform inhibitory TME signals into pro-inflammatory signals like IL-4 receptor ectodomains with IL-7 receptor endodomains (Mohammed et al., 2017) or with IL-2 and IL-15 receptor shared $\beta$ - subunits (Wilkie et al., 2010) that convert inhibitory IL-4 signals into homeostatic IL-7, IL-2 or IL-15 signals. T cells and CAR-T cells evolved to express a predominantly negative version of the proapoptotic receptor Fas have increased resistance to Fas ligand (FasL) apoptotic signals present in the TME. This contributes to increased anti-tumor activity in syngenic mice with various solid or haematologic malignancies (Yamamoto et al., 2019).

In conjunction, the availability of oxygen, amino acids like tryptophan, arginine, and cysteine and other nutrients affects the metabolism, activity, and differentiation of $\mathrm{T}$ cells, and the general deficiency of these nutrients in the TME can evoke T-cell inhibitory pathways or suppress T-cells (Xu et al., 2019). Arginine has important roles in the regulation of $\mathrm{T}$ cells and is compatible with cancer cells and other TME cells for this amino acid might 
result in reducing $\mathrm{T}$ cell functions. In vitro, pretreatment of TCR-transgenic $\mathrm{T}$ cells with arginine raised anti-tumor activity of $\mathrm{T}$ cells with melanomas expressing the cognate antigen after infusion into mice (Geiger et al., 2016).

Elevated potassium levels in the TME have affected T-cell nutrient uptake owing to metabolic shifts and epigenetic changes that maintain T-cell stem and also inhibit T-cell differentiation as effector phenotypes. On the other hand, pretreatment of $\mathrm{T}$ cells with potassium in vitro boosts the survival and anti-tumor function of human $\mathrm{T}$ cells adopted in mouse xenograft models (Vodnalaet al., 2019). Production of the antioxidant enzyme catalase, in addition to the mentioned strategies those made $\mathrm{T}$ cells capable of overcoming granulocyte-mediated oxidative stress in vitro (Ando etal., 2008). All of these observations demonstrate that modulation and development of $\mathrm{T}$-cell metabolic pathways may provide new possibilities to improve the effectiveness of CAR-T cells in patients with solid tumors.

\section{Altering theTME milieu:}

For promoting the CAR-T cells function rather than TME's inhibitory signals, CAR$\mathrm{T}$ cells may be engineered to include immuno-stimulatory signals. These signals also induce an endogenous anti-tumor response by remodeling the solid tumor microenvironment. Because antigen escape is still a crucial issue with CAR-T cell therapy, endogenous immune cells can need to be recruited for optimization of the anti-tumor immune response. Promoting CAR-T cells to secrete immuno-stimulatory cytokines that not only encourage $\mathrm{T}$ cell proliferation, survival, and anti-tumor action but also alter TME's immune environment is a potential research subject. Multiple cytokines were investigated for engineering such types of armored CAR-T cells. Such CAR-T cells are also recognized as T cells redirected for universal cytokine killing (TRUCKs) (Chmielewskiet al., 2014). The thymoma mouse model preconditioned using cyclophosphamide to promote the greasing of anti-CD19 CAR-T cells that led to greater levels of IL-12, which has a multifaceted role in the immune response comprising $\mathrm{T}$ cells and NK cells activation. Hence, developing CAR-T cells to express IL-12 resulted in increased cytotoxicity and resistance to in vitro inhibition mediated by Treg cells, elevated engraftment of anti-CD19 CAR-T cells without preconditioning for chemotherapy and increased in vivo anti-tumor activity (Curran et al., 2015). In addition to IL-12 expression, CAR-T cells were dramatically expanded from limited numbers of cells isolated from umbilical cord blood, presenting the potential of CAR-T cells produced from small volumes of cord blood for patients with haematological malignancies undergoing allogeneic haematopoietic stem cell transplantation (HSCT) (Curran et al., 2015).

The therapeutic potential of CAR-T cells secreting IL-12 has been shown in preclinical studies, while current and prospective clinical trials will consider the dose dependent variability in both immune responses and toxicity.IL-15 also plays a vital essential in differentiation, homeostasis and survival of $\mathrm{T}$ cells and NK cells. In comparison to unarmored anti-CD19 CAR-T cells with reduced apoptosis and PD-1 expression, in mouse xenograft models of Burkitt lymphoma, and in patient derived B cell chronic lymphocytic leukemia (CLL) samples in vitro, the expansion and anti-tumor function of armored CAR-T cells expressing IL-15 has been enhanced (Hoyos et al., 2010). In addition, fusing of the IL15 receptor signaling domain to the CD28 co-stimulatory signaling domain of an anti-CD19 
CARresulted in developing of CAR-T cells with strengthened in vivo persistence in preclinical studies and full remission in ALL patients (Nair et al.,2019). Thus, IL-15 can boost CAR-T cells, survival and function in vivo although for this cytokine there is little evidence of the effects on the TME in immunocompetent models. Engineering techniques to 'backpack' large with nanogels engineering methods using nanogels to 'backpack' large levels of IL-15 onto CAR-T cells revealed that high doses of IL-15 can be transmitted to tumor sites without systemic toxicity in preclinical trials (Tang et al., 2018). IL-18 is a multifunctional cytokine that is synthesized by macrophages. IL-18 can alter the phenotype of T cells and NK cells, and has been shown to improve human effector $\mathrm{T}$ cell engraftment and inhibit that of immunosuppressive human Treg cells in mice (Carroll et al., 2008).

Multiple groups have shown that IL-18 secreting armored CAR-T cells have increased performance compared with their unarmored CAR-T cells. They can also modify the inflammatory TME and recruit endogenous immune cells in syngeneic immunocompetent mice to the tumor (Avanzi et al., 2018). In addition, IL-18 secreting CAR-T cells were correlated with expanded accumulation of M1-polarized proinflammatory macrophages in the TME, suppression of M2-polarized anti-inflammatory macrophages and Treg cells, and mobilization of endogenous $\mathrm{T}$ cells in these mice (Chmielewskiand Abken, 2017). Systemic administration of IL-18 is well tolerated in patients, with low toxicity (Robertson etal., 2006). However, IL-18 has pathogenic effects in autoimmune diseases (Sedimbiet al., 2013) and may also encourage cell proliferation, angiogenesis, immune escape and metastasis (Vidal-Vanaclochaet al., 2006). Therefore, caution is needed when using CAR-T cells secreting IL-18 in the clinic. Explored cytokines were additionally used in preclinical trials to improve CAR-T cell activity.

\section{Toxicity of CAR-T Cells}

The several pathways of CAR-T cells may cause toxicity. If the tumor-associated antigen (TAA) to which the CAR is targeted is expressed in normal tissues, those normal tissues may be affected, as anti-CD19 CAR-T cells can deplete normal B cells (Gruppet al., 2013). CAR-T cells can also cause damage to normal tissues by responding suddenly with a protein that is not expressed on tumor cells (Cameron et al., 2013). Upon infusion of the CAR-T cells, acute anaphylaxis and tumor lysis syndrome (TLS) may happen. The cytokinerelease syndrome (CRS) is considered the most severe as well as well-described toxicity of CAR-T cells. This is a series of symptoms such as fever and hypotension triggered by cytokines produced by the T-cells infected with engineering (Casucciet al., 2015). Conjunctual neurological toxicity can be induced by CAR-T cell therapy with CRS or in its absence (Kochenderferet al., 2015). Logically, by insertional mutagenesis, the gene-therapy vector may be capable of viral replication or inducing a secondarytumor (Hacein-BeyAbinaet al., 2008). However, none of these toxicities associated with the gene-therapy vector has been reported in clinical trials of CAR-T cell therapy (Scholler et al., 2012).

\section{CAR-T cell toxicities by damaging normal cells that express the targeted antigen:}


Destroying tissues expressing the CAR recognized antigen by CAR-T cells may occur. This toxicity mechanism may be compromised by an extensive check for the expression of a specific antigen on normal tissue during preclinical CARs studies (Qin et al., 2015). Three patients with metastatic renal cell carcinoma who had CAR-T cell therapy infusions targeting carboxy anhydrase-IX encountered grade 3-4 increases in alanine aminotransferase, aspartate aminotransferase, or total bilirubin (Lamers et al., 2011). Liver biopsies of affected patients revealed cholangitis with an infiltration of $\mathrm{T}$ cells surrounding the bile ducts, and bile duct epithelial cells were found to express carboxy-anhydrase-IX unexpectedly (Lamers et al., 2006). In addition, Ametastatic patient with colorectal cancer obtained an injection of CAR-T cells directed against the ERBB2 antigen (Her-2/neu). The patient experienced acute respiratory failure and pulmonary oedema that needed mechanical ventilation and eventually died. The patient's pulmonary toxicity and eventual death were suspected as being due to ERBB2 expression on normal lung tissue (Morgan et al.,2010).

\section{Cross-reactivity of a CAR with a non targeted protein:}

Theoretically, organ damage can occur when CAR-T cells cross-react with an identical antigen to the tumor-expressed target antigen expressed on normal tissue. This toxicity was not reported in clinical trials of CAR-T cells but was noted in T cell genetically engineered clinical trials to express T cell receptors (Morgan et al., 2013).

\section{Allergic reactions and TLS:}

Allergic reactions against CAR-T cells have been reported. A patient with pleural mesothelioma received several infusions of an anti-mesothelin CAR transduced autologous $\mathrm{T}$ cells. The patient was tolerated to the first two cell therapy infusions well, but he had anaphylaxis and cardiac arrest 1 minute after finishing his third infusion with dramatically elevated serum tryptase levels. He received cardiopulmonary resuscitation and recovered (Mauset al., 2013). In certain cases, however, chemotherapy may have triggered TLS; in the absence of previous conditioning chemotherapy, the infusion of CAR-T cells has contributed to TLS (Kochenderfer et al., 2013).

\section{Future Directions}

The main objective of cancer immunotherapy is eradication of cancerous cells without the risk of traditional therapies. The preclinical research and early clinical tests have succeeded in engineered CAR-T cells promising to achieve this goal. CAR-T cell therapy has many advantages including HLA's independent identification of target antigens, wide predictive validity to several patients, ability of resolving tumor escape and the rapidly delivery of tumor specific T cells population. Effective use of CAR-T cell technology would involve careful detection of target antigens that are expressed uniquely on cancerous cells and reduce the risk of toxicity. Recent clinical trials have also resulted in the CAR-T cell therapy's effectiveness in survival after adoptive transfer (Kaloset al., 2011). We can achieve this success by multiple injections of engineered $T$ cells that can artificially increase the persistence of $\mathrm{T}$ cells and strengthen the anti-tumor effectiveness in a cancer mouse model 
(Brentjenset al., 2007). While CAR-T cell technology should allow the proliferation, persistence and retention of targeted cytotoxic function for a lifetime for a single injection of $\mathrm{T}$ cells otherwise the treatment is extremely expensive and unsuccessful. Therefore, continued research into the components that affect tumor-targeted $\mathrm{T}$ cell persistence is a major issue. Signaling, tumor burden, conditioning chemotherapy, T cell phenotype and the use of additional cytokines were all addressed. In relation, the production of an immune response against the adoptively transferred $\mathrm{T}$ cells has been demonstrated in several studies (Jensen et al., 2010). This trend has reduced the survival and efficacy of cells that were transferred to adoption. The creation of less immunogenic CARs such as humanized scFvs, development of tolerance and/or enhancement of immunosuppression must be an area to work on for the successful application of CAR-T cell therapy.

While CAR-T cell technology has shown success in hematological malignancies, further studies are still needed for this therapy application in solid tumors. Despite this, some researchers have concentrated on the potential to grow tumor-targeted $\mathrm{T}$ cells; upon entering the suppressive tumor microenvironment, it is likely that CAR-modified T cells may become ineffective. So, the future of this technology lies in the generation of CAR-T cells that avoid the energy and apoptosis that exists inside the tumor microenvironment (TME) for all immune effectors. Besides overcoming the aggressive tumor microenvironment (TME), CAR-T cells should also have the capability of recruiting an endogenous anti-tumor response. Because targeting a single antigen on a tumor cell may not only initially result in a reduction in tumor burden, but may also select tumor cells that lack this target antigen for expansion. Thus, genetic modifications of $\mathrm{T}$ cells can only directly target the tumor and theoretically resolve the aggressive TME without recruiting and stimulating the endogenous immune system, this therapy is likely not to serve to cure patients. What is more, engineered $\mathrm{T}$ cells stimulate an endogenous anti-tumor response including TILs, NK cells and the innate immune system. This activation will cause epitope spreading on the cancerous cells against several antigens and restricting tumor escape from theantigen.

Despite the significant progress in this technology over a relatively short period, the success of all cancer therapies is only assessed by the impact they have on clinic patients. Multi-institutional clinical trials would need to be performed to better identify the efficacy of this treatment, which require considerable researchinvestment and funding. It is worth remembering that these expenditures may be prohibitive, and that the funding mechanism currently available is inadequate to cover their costs. However, there is a new hope that resources will be available for the production of this potential immunotherapy, with the recent breakthrough responses seen in smaller single institutional trials.

\section{Conclusion and Suggestion:}

In this review, we discussed the characteristics which use CAR-T cells to transform into effective tumor immunotherapy. To date, the target antigen, signaling domain, traffic capacity, durability, retained function, thestatus of patient illness, and theconditioning regime have all been dramatically challenging. Thereby, we can conclude that the prospect of this technology lies in CAR-T cell engineering which can overcome aggressive TMEs and recruiting an endogenous tumor response. The final task for researchers in this field is to 
carry out clinical trials and secure the funding needed to complete their clinical trials. This immunotherapy continues to progress and more records of successful malignancy eradication occur.

\section{Conflict of Interest}

None

\section{Funding:}

None

\section{References}

Adusumilli PS, et al. (2018). A phase I clinical trial of malignant pleural disease treated with regionally delivered autologous mesothelin- targeted CAR T cells: safety and efficacy - a preliminary report. Presented at the American Society of Gene and Cell $21^{\text {st }}$ Annual Meeting.

Alabanza, L. et al. (2017). Function of novel anti- CD19 chimeric antigen receptors with human variable regions is affected by hinge and transmembrane domains. Mol. Ther, $25,2452-65$.

Ali SA, Shi V, Maric I, Wang M, Stroncek DF, Rose JJ, et al. (2016). T cells expressing an anti-B-cell maturation antigen chimeric antigen receptor cause remissions of multiple myeloma. Blood, 128, 1688-700.

Ando T, et al. (2008). Transduction with the antioxidant enzyme catalase protects human T cells against oxidative stress. J Immunol,181, 8382-90.

Angel M, Yanik MF (2010). Innate immune suppression enables frequent transfection with RNA encoding reprogramming proteins. PloS One, 5(7), e11756.

Avanzi MP, et al. (2018). Engineered tumor- targeted T cells mediate enhanced anti- tumor efficacy both directly and through activation of the endogenous immune system. Cell Rep, 23, 2130-41.

Bailey SR, Maus MV (2019). Gene editing for immune cell therapies. Nat. Biotechnol, 37, 1425-34.

Barrett DM, Liu X, Jiang S, June CH, Grupp SA, Zhao Y (2013). Regimen-specific effects of RNA-modified chimeric antigen receptor $\mathrm{T}$ cells in mice with advanced leukemia. Human Gene Therap, 24(8), 717-27.

Beatty GL, Haas AR, Maus MV, Torigian DA, Soulen MC, Plesa G, Chew A, Zhao Y, Levine BL, Albelda SM, Kalos M, June CH (2014. Mesothelin-specific chimeric antigen receptor mRNA-engineered $\mathrm{T}$ cells induce anti-tumor activity in solid malignancies. Cancer Immunol Res, 2(2), 112-120.

Beavis PA, et al. (2017). Targeting the adenosine 2A receptor enhances chimeric antigen receptor T cell efficacy. J Clin Invest, 127, 929-41.

Bolhassani A, Khavari A, Orafa Z (2014). Nanotechnology and nanomaterials, application of nanotechnology in drug delivery, electroporation - advantages and drawbacks for delivery of drug, gene and vaccine. In: Application of Nanotechnology in Drug Delivery, 11, 369-98. 
Brentjens RJ, Santos E, Nikhamin Y, et al. (2007). Genetically targeted T cells eradicate systemic acute lymphoblastic leukemia xenografts. Clin Cancer Re, 13, 5426-35.

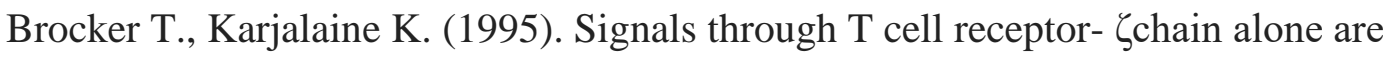
insufficient to prime resting T lymphocytes. J Exp Med, 181, 1653-9.

Brown CE, Alizadeh D, Starr R, Weng L, Wagner JR, Naranjo A, Ostberg JR, Blanchard MS, Kilpatrick J, Simpson J, Kurien A, Priceman SJ, Wang X, Harshbarger TL, D’Apuzzo M, Ressler JA, Jensen MC, Barish ME, Chen M, Portnow J, Forman SJ, Badie B. (2016). Regression of Glioblastoma after Chimeric Antigen Receptor T-Cell Therapy. N Engl J Med, 375(26), 2561-9.

Brown CE, Badie B, Barish ME, Weng L, Ostberg JR, Chang WC, Naranjo A, Starr R, Wagner J, Wright C, Zhai Y, Bading JR, Ressler JA, Portnow J, D'Apuzzo M, Forman SJ, Jensen MC (2015). Bioactivity and safety of IL13Ralpha2-redirected chimeric antigen receptor CD8+ T cells in patients with recurrent glioblastoma. Clin Cancer Res, 21(18), 4062-72.

Busch DH, Fräßle SP, Sommermeyer D, Buchholz VR, Riddell SR (2016). Role of memory

T cell subsets for adoptive immunotherapy. SeminImmunol, 28, 28-34.

Cameron BJ, Gerry AB, Dukes J, et al. (2013). Identification of a Titin-derived HLA-A1-

presented peptide as a cross-reactive target for engineered MAGE A3-directed T cells. SciTransl Med, 5(197), 197ra103.

Cardarelli F, Digiacomo L, Marchini C, Amici A, Salomone F, Fiume G, Rossetta A, Gratton

E, Pozzi D, Caracciolo G (2016). The intracellular trafficking mechanism of Lipofectamine-based transfection reagents and its implication for gene delivery. Scient. Reports, 6, 25879.

Carroll RG, et al. (2008). Distinct effects of IL-18 on the engraftment and function of human effector CD8 T cells and regulatory T cells. PLOS ONE, 3, e3289.

Caruana I, et al. (2015) Heparanase promotes tumor infiltration and antitumor activity of CAR- redirected T lymphocytes. Nat Med, 21, 524-529.

Casucci M, Hawkins RE, Dotti G, Bondanza A (2015). Overcoming the toxicity hurdles of genetically targeted T cells. Cancer ImmunolImmunother, 64(1), 123-30.

Cellectis, Preliminary Data from Servier and Pfizer's UCART19 Product Candidate Shows

High Complete Remission Rate Across Two Phase I Adult and Pediatric Acute Lymphoblastic Leukemia Trials. New York, Dec 2017.

Centers for Disease Control and Prevention. United States Cancer Statistics: Data Visualizations.https://www.cdc.gov/cancer/dataviz (2019).

Chang ZL, Lorenzini MH, Chen X, Tran U, Bangayan NJ, Chen YY.(2018). Rewiring T-cell responses to soluble factors with chimeric antigen receptors. Nat Chem Biol,14(3), 317-24.

.Cherkassky L, et al. (2016). Human CAR T cells with cellintrinsic PD-1 checkpoint blockade resist tumormediated inhibition. J Clin Invest, 126, 3130-44.

Chmielewski M, Abken H (2017). CAR T cells releasing IL-18 convert to T-

BethighFoxO1loweffectors that exhibit augmented activity against advanced solid tumors. Cell Rep, 21, 3205-19.

Chmielewski M, Hombach AA, Abken, H (2014). Of CARs and TRUCKs: chimeric antigen 
receptor (CAR) T cells engineered with an inducible cytokine to modulate the tumor stroma. Immunol Rev, 257, 83-90.

Choi BD, et al. (2019). CAR- T cells secreting BiTEs circumvent antigen escape without detectable toxicity. Nat Biotechnol, 37, 1049-58.

Cho JH, Collins JJ, Wong WW (2018). Universal chimeric antigen receptors for multiplexed and logical control of $\mathrm{T}$ cell responses. Cell, 173, 1426-38.

Chong EA, et al. (2017). Phase I/II study of pembrolizumab for progressive diffuse large B cell lymphoma after anti- CD19 directed chimeric antigen receptor modified T cell therapy. Blood, 130, 4121.

Condomines M, et al. (2015). Tumor- targeted human T cells expressing CD28-based chimeric antigen receptors circumvent CTLA-4 inhibition. PLOS ONE, 10, $\mathrm{e} 0130518$.

Cullen BR, Lomedico PT, Ju G (1984). Transcriptional interference in avian retrovirusesimplications for the promoter insertion model of leukaemogenesis. Nature, 307(5948), 241-5.

Curran KJ, Seinstra BA, Nikhamin Y, Yeh R, Usachenko Y, van Leeuwen DG, Purdon T, Pegram HJ, Brentjens RJ (2015. Enhancing antitumor efficacy of chimeric antigen receptor T cells through constitutive CD40L expression. MolTher, 23(4), 769-78.

Cyranoski D (2016).bCRISPR gene-editing tested in a person for the first time. Nature, 539 (7630), 479.

Dai H, Wang Y, Lu X, Han W (2016). Chimeric antigen receptors modified T-cells for cancer therapy. J Natl Cancer Inst, 108(7),pii, djv439.

DeWitt MA, Corn JE, Carroll D (2017). Genome editing via delivery of Cas9 ribonucleoprotein. Methods, 121-122, 9-15.

Di Stasi A, et al. (2009). T lymphocytes coexpressing CCR4 and a chimeric antigen receptor targeting CD30 have improved homing and antitumor activity in a Hodgkin tumor model. Blood, 113, 6392-402.

Dwivedi A, Karulkar A, Ghosh S, Rafiq A, Purwar R (2019). Lymphocytes in cellular therapy: functional regulation of CAR T cells. Front. Immunol, 9, 3180.

Fedorov VD, Themeli M, Sadelain M (2013). PD-1- and CTLA-4-based inhibitory chimeric antigen receptors (iCARs) divert offtargetimmunotherapy responses. SciTranslatl Med, 5 (215), 215 ra172.

Feucht J, et al. (2019). Calibration of CAR activation potential directs alternative $\mathrm{T}$ cell fates and therapeutic potency. Nat Med, 25, 82-8.

Geiger R, et al. (2016). L- arginine modulates T cell metabolism and enhances survival and anti- tumor activity. Cell, 167, 829-42.

Glienke W, Esse R, Priesner C, Suerth JD, Schambach A, Wels WS, Grez M, Kloess S, Arseniev L, Koehl U (2015). Advantages and applications of CAR-expressing natural killer cells. Front. Pharmacol, 6, 21.

Grada Z, Hegde M, Byrd T, Shaffer DR, Ghazi A, Brawley VS, Corder A, Schonfeld K, Koch J, Dotti G, Heslop HE, Gottschalk S, Wels WS, Baker ML, Ahmed N (2013).TanCAR: A novel bispecific chimeric antigen receptor for cancer immunotherapy. Molecular therapy. Nucleic Acids, 2, e105.

Gross G, Waks T, Eshhar Z (1989). Expression of immunoglobulin-Tcell receptor chimeric 
molecules asfunctional receptors with antibody-type specificity. Proc. Natl. Acad. Sci. USA, 86(24), 10024-8.

Grupp SA, Kalos M, Barrett D, et al. (2013). Chimeric antigen receptor-modified T cells for acutelymphoidleukemia. N Engl J Med, 368(16), 1509-18.

Guedan S et al. (2014). ICOS- based chimeric antigen receptors program bipolar T H17/TH1 cells. Blood, 124, 1070-80.

Hacein-Bey-Abina S, Garrigue A, Wang GP, et al. (2008). Insertional oncogenesis in 4 patients after retrovirus-mediated gene therapy of SCID-X1. J Clin Invest, 118(9), 3132-42.

Hammill JA, VanSeggelen H, Helsen CW, Denisova GF, Evelegh C, Tantalo DGM, Bassett JD, BramsonJL (2015). Designed ankyrin repeat proteins are effective targeting elements for chimeric antigen receptors. J Immunother Cancer, 3, 55.

Han X, Cinay GE, Zhao Y, Guo Y, Zhang X, Wang P (2017).Adnectin-Based Design of Chimeric Antigen Receptor for T Cell Engineering.MolTher, 25(11), 2466-76.

Hardaway JC, Prince E, Arepally A, Katz SC (2018). Regional infusion of chimeric antigen receptor $\mathrm{T}$ cells to overcome barriers for solid tumor immunotherapy. $\mathrm{J}$ VascIntervRadiol, 29, 1017-21.

Hedrick SM (1993). Chimeric T cell receptor-immunoglobulin molecules function and applications. Int Rev Immunol, 10, 279-90.

Hingorani SR, et al. (2018). HALO 202: Randomized phase II study of PEGPH20 plus Nabpaclitaxel/gemcitabine versus Nab- paclitaxel/gemcitabine in patients with untreated, metastatic pancreatic ductal adenocarcinoma. J ClinOncol, 36, 359-66.

Hombach AA, Heiders J, Foppe M, Chmielewski M, Abken H (2012). OX40 costimulation by a chimeric antigen receptor abrogates CD28 and IL-2 induced IL-10 secretion by redirected CD4+T cells. Oncoimmunology, 1, 458-66.

Hombach A, Hombach AA, Abken H (2010). adoptive immunotherapy with genetically engineered T cells: modification of the IgG1 Fc 'spacer' domain in the extracellular moiety of chimeric antigen receptors avoids 'off- target' activation and unintended initiation of an innate immune response. Gene Ther, 17, 1206-13.

Hoos A (2016). Development of immuno-oncology drugs - from CTLA4 to PD1 to the next generations. Nat Rev Drug Discov, 15, 235-47.

Hoyos V, et al. (2010). Engineering CD19-specific T lymphocytes with interleukin-15 and a suicide gene to enhance their anti- lymphoma/leukemia effects and safety. Leukemia, 24, 1160-70.

Inaguma $\mathrm{Y}$ et al. (2014). Construction and molecular characterization of a T- cell receptor like antibody and CAR - T cells specific for minor histocompatibility antigen HA1H.Gene ther, 21, 575- 584.

Islam MA, Reesor EK, Xu Y, Zope HR, Zetter BR, Shi J (2015). Biomaterials for mRNA delivery. BiomatSci, 3(12), 1519-33.

Jensen MC, Popplewell L, Cooper LJ, et al. (2010).Antitransgene rejection responses contribute to attenuated persistence of adoptively transferred CD20/CD19-specific chimeric antigen receptor redirected $\mathrm{T}$ cells in humans. Biol Blood Marrow Transplant, 16, 1245-56.

Jensen MC, Riddell SR (2015). Designing chimericantigen receptors to effectively and safely 
targettumors. Curr. Opin. Immunol, 33, 9-15.

Jin Z, Maiti S, Huls H, Singh H, Olivares S, Mates L, Izsvak Z, Ivics Z, Lee DA, Champlin RE, Cooper LJ (2011). The hyperactive sleeping beauty transposase SB100X improves the genetic modification of $\mathrm{T}$ cells to express a chimeric antigen receptor. Gene Ther, 18(9), 849-856.

John LB, Devaud C, Duong CP, Yong CS, Beavis PA, Haynes NM, Chow MT, Smyth MJ, Kershaw MH, Darcy PK (2013). Anti-PD-1 antibody therapy potently enhances the eradication of established tumors by gene-modified T cells. Clin Cancer Res, 19(20), 5636-46.

Juneja VR, McGuire KA, Manguso RT, LaFleur MW, Collins N, Haining WN, Freeman GJ, Sharpe AH (2017). PD-L1 on tumor cells is sufficient for immune evasion in immunogenic tumors and inhibits CD8 T cell cytotoxicity. J Experim Med, 214(4), 895-904.

Junttila MR, de Sauvage FJ (2013). Influence of tumour micro- environment \} heterogeneity on therapeutic response. Nature, 501, 346-54.

Kalos M, Levine BL, Porter DL,et al. (2011). T cells with chimeric antigen receptors have potent antitumor effects and can establish memory in patients with advanced leukemia. SciTransl Med, 3, 95ra73.

Kantarjian H, et al. (2017).Blinatumomab versus chemotherapy for advanced acute lymphoblastic leukemia. N Engl J Med, 376, 836-47.

Kawalekar OU et al. (2016). Distinct signaling of coreceptors regulates specific metabolism pathways and impacts memory development in CAR T cells. Immunity, 44, 712.

Kloss CC, et al. (2018). Dominant- negative TGF- $\beta$ receptor enhances PSMA- targeted human CAR T cell proliferation and augments prostate cancer eradication. MolTher, 26, 1855-66.

Kloss CC, Condomines M, Cartellieri M, Bachmann M, Sadelain M (2013). Combinatorial antigen recognition with balanced signaling promotes selective tumor eradication by engineered T cells. Nat. Biotechnol, 31(1), 71-5.

Kobold S, et al. (2015). Impact of a new fusion receptor on PD-1-mediated immunosuppression in adoptive T cell therapy. J Natl Cancer Inst, 107, djv146.

Kochenderfer JN, Dudley ME, Carpenter RO, et al. (2013). Donor-derived CD19-targeted T cells cause regression of malignancy persisting after allogeneic hematopoietic stem cell transplantation. Blood, 122(25), 4129-39.

Kochenderfer JN, Dudley ME, Kassim SH, et al. (2015). Chemotherapy-refractory diffuse large B-cell lymphoma and indolent B-cell malignancies can be effectively treated with autologous $\mathrm{T}$ cells expressing an anti-CD19 chimeric antigen receptor.JClinOncol, 33(6), 540-9.

Kudo K, et al. (2014). T lymphocytes expressing a CD16 signaling receptor exert antibodydependent cancer cell killing. Cancer Res, 74, 93-103.

Kuhn NF, et al. (2019). CD40 ligand- modified chimeric antigen receptor T cells enhance antitumor function by eliciting an endogenous antitumor response. Cancer Cell, 35, 473-488.e6.

Lamers CH, Sleijfer S, Vulto AG, et al. (2006). Treatment of metastatic renal cell carcinoma 
with autologous T-lymphocytes genetically retargeted against carbonic anhydrase IX: first clinical experience. J ClinOncol, 24(13), e20-e22.

Lamers CH, Willemsen R, van Elzakker P, et al. (2011). Immune responses to transgene and retroviral vector in patients treated with ex vivo-engineered T cells. Blood, 117(1), 72-82.

Lee YG, et al. (2019). Use of a single CAR T cell and several bispecific adapters facilitates eradication of multiple antigenically different solid tumors. Cancer Res, 79, 387-96.

Li AM, et al. (2018). Checkpoint inhibitors augment CD19-directed chimeric antigen receptor (CAR) T cell therapy in relapsed B- cell acute lymphoblastic leukemia. Blood, 132, 556.

Liang X, Potter J, Kumar S, Zou Y, Quintanilla R, Sridharan M, Carte J, Chen W, Roark N, Ranganathan S, Ravinder N, Chesnut JD (2015). Rapid and highly efficient mammalian cell engineering via Cas9 protein transfection. J Biotechnol, 208, 44-53.

Li S, et al. (2017). Enhanced cancer immunotherapy by chimeric antigen receptor-modified $\mathrm{T}$ cells engineered to secrete checkpoint inhibitors. Clin Cancer Res, 23, 6982-92.

Liu X, et al. (2016). A chimeric switch- receptor targeting PD1 augments the efficacy of second- generation CAR T cells in advanced solid tumors. Cancer Res, 76, 1578-90.

Lo AS, et al. (2008). Harnessing the tumour- derived cytokine, CSF-1, to co- stimulate T- cell growth and activation. MolImmunol, 45, 1276-87.

Locke FL, Neelapu SS, Bartlett NL, Siddiqi T, Chavez JC, Hosing CM, et al. (2017). Phase 1 results of ZUMA-1: a multicenter study of KTE-C19 anti-CD19 CAR T cell therapy in refractory aggressive lymphoma. MolTher, 25, 285-95.

Lohmueller JJ, Ham JD, Kvorjak M, Finn OJ (2017). mSA2 affinity- enhanced biotinbinding CAR T cells for universal tumor targeting. Oncoimmunology, 7, e1368604.

MacLeod DT, Antony J, Martin AJ, Moser RJ, Hekele A, Wetzel KJ, Brown AE, Triggiano MA, Hux JA, Pham CD, Bartsevich VV, Turner CA, Lape J, Kirkland S, Beard CW, Smith J, Hirsch ML, Nicholson MG, Jantz D, McCreedy B (2017). Integration of a CD19 CAR into the TCR alpha chain locus streamlines production of allogeneic gene-edited CAR T cells. MolTher, 25(4), 949-61.

Mahadeo KM, et al. (2019). Management guidelines for paediatric patients receiving chimeric antigen receptor T cell therapy. Nat Rev ClinOncol, 16, 45-63.

Maher J., Brentjens R. J., Gunset G., Riviere I., Sadelain, M. (2002). Human T- lymphocyte cytotoxicity and proliferation directed by a single chimeric TCR $\zeta / C D 28$ receptor. Nat. Biotechnol, 20, 70-5.

Majzner RG, Mackall CL (2018).Tumor antigen escape from CAR T- cell therapy. Cancer Discov, 8, 1219-26.

Manuri P, Wilson MH, Maiti SN, Mi T, Singh H, Olivares S, Dawson MJ, Huls H, Lee DA, Rao PH, Kaminski JM, Nakazawa, Y, Gottschalk S, Kebriaei P, Shpall EJ, Champlin RE, Cooper LJ (2010). piggyBac transposon/transposase system to generate CD19specific T cells for the treatment of Blineage malignancies. Human Gene Ther, 21(4), 427-37.

Mardomi A, Abediankenari S (2018). Matrix metalloproteinase 8: could it benefit the CART cell therapy of solid tumors? - a- Commentary on therapeutic potential. Cancer Microenviron, 11, 93-6. 
Mata M et al. (2017). Inducible activation of MyD88 and CD40 in CAR T cells results in controllable and potent antitumor activity in preclinical solid tumor models. Cancer Discov, 7, 1306-19.

Maus MV, Haas AR, Beatty GL, et al. (2013). T cellsexpressing chimeric antigen receptors can cause anaphylaxis in humans. Cancer Immunol Res, 1(1), 26-31.

Miliotou AN, Papadopoulou LC (2018). CAR T-cell Therapy: A New Era in Cancer Immunotherapy. Current Pharmaceutical Biotechnology, 19, 5-18.

Mitchison NA (1955). Studies on the immunological response to foreign tumor transplants in the mouse. I. The role of lymph node cells in conferring immunity by adoptive transfer. J Exp Med, 102, 157-77.

Moffett HF, Coon ME, Radtke S, Stephan SB, McKnight L, Lambert A, Stoddard BL, Kiem HP, Stephan MT (2017). Hit and-run programming of therapeutic cytoreagents using mRNA nanocarriers. Nat Commun, 8(1), 389.

Mohammed S, et al. (2017). Improving chimeric antigen receptor- modified T cell function by reversing the immunosuppressive tumor microenvironment of pancreatic cancer. MolTher, 25, 249-58.

Monjezi R, Miskey C, Gogishvili T, Schleef M, Schmeer M, Einsele H, Ivics Z, Hudecek M (2017). Enhanced CAR T-cell engineering using non-viral Sleeping Beauty transposition from minicircle vectors. Leukemia, 31(1), 186- 94.

Moon EK, et al. (2014). Multifactorial T- cell hypofunction that is reversible can limit the efficacy of chimeric antigen receptor- transduced human T cells in solid tumors. Clin Cancer Res, 20, 4262-73.

Moon EK, et al. (2011). Expression of a functional CCR2 receptor enhances tumor localization and tumor eradication by retargeted human $\mathrm{T}$ cells expressing a mesothelin- specific chimeric antibody receptor. Clin Cancer Res, 17, 4719-30.

Morgan MA, Schambach A (2018). Engineering CAR- T cells for improved function against solid tumors. Front Immunol, 9, 2493.

Morgan RA, Chinnasamy N, Abate-Daga D, et al. (2013). Cancer regression and neurological toxicity following anti-MAGE-A3 TCR gene therapy. J Immunother, 36(2), 133-51.

Morgan RA, Yang JC, Kitano M, Dudley ME, Laurencot CM, Rosenberg SA (2010). Case report of a serious adverse event following the administration of $\mathrm{T}$ cells transduced with a chimeric antigen receptor recognizing ERBB2. MolTher, 18(4), 843-51.

Nagarsheth N, Wicha MS, Zou W (2017). Chemokines in the cancer microenvironment and their relevance in cancer immunotherapy. Nat Rev Immunol, 17, 559-72.

Nair S, et al. (2019). Functional improvement of chimeric antigen receptor through intrinsic interleukin-15Rasignaling. Curr Gene Ther, 19, 40-53.

Newick K, et al. (2016). Augmentation of CAR T- cell trafficking and antitumor efficacy by blocking protein kinase A localization. Cancer Immunol Res, 4, 541-51.

Oldham RAA, Medin JA (2017). Practical considerations for chimeric antigen receptor design and delivery. Expert Opin Biologic Ther, 17(8), 961-78.

Oren R et al. (2014). Functional comparison of engineered Tcells carrying TCR versus TCRlike antibody based chimeric/antigen receptors indicates affinity avidity thresholds. J. Immunol, 193, 5733 - 5743.

Ott PA, Hu Z, Keskin DB, Shukla SA, Sun J, Bozym DJ, et al. (2017). An immunogenic 
personal neoantigen vaccine for patients with melanoma. Nature, 547, 217-21.

Pan J, et al. (2019). CD22 CAR T- cell therapy in refractory or relapsed B acute

lymphoblastic leukemia. Leukemia, 33, 2854-66.

Park JH, et al. (2018). A phase I first- in-human clinical trial of CD19-targeted 19-28z/4-

1BBL "armored" CAR T cells in patients with relapsed or refractory NHL and CLL including Richter's transformation. Blood, 132, 224.

Park JH, Riviere I, Gonen M, Wang X, Senechal B, Curran KJ, et al. (2018). Long-term follow-up of CD19 CAR therapy in acute lymphoblastic leukemia. N Engl J Med, $378,449-5$.

Petersen CT, et al. (2018). Improving T- cell expansion and function for adoptive T- cell therapy using ex vivo treatment with PI3K Adv, 2, 210-23.

Piscopo NJ, Mueller KP, Das A, Hematti P, Murphy WL, Palecek SP, Capitini CM, Saha K (2018). Bioengineering Solutions for manufacturing challenges in CAR T cells. Biotechnol J, 13(2), 1-20.

Porter DL, Hwang WT, Frey NV, Lacey SF, Shaw PA, Loren AW, et al. (2015). Chimeric antigen receptor $\mathrm{T}$ cells persist and induce sustained remissions in relapsed refractory chronic lymphocytic leukemia. SciTrans1 Med, 7, 303ra139.

Postow MA, Callahan MK, Wolchok JD (2015). Immune checkpoint blockade in cancer therapy. J ClinOncol, 33, 1974-82.

Priceman SJ, Forman SJ, Brown CE (2015). Smart CARs engineered for cancer immunotherapy. Curr. OpinOncol, 27(6), 466-74.

Qasim W, Zhan H, Samarasinghe S, Adams S, Amrolia P, Stafford S, Butler K, Rivat C, Wright G, Somana K, Ghorashian S, Pinner D, Ahsan G, Gilmour K, Lucchini G, Inglott S, Mifsud W, Chiesa R, Peggs KS, Chan L, Farzeneh F, Thrasher AJ, Vora A, Pule M, Veys P (2017). Molecular remission of infant B-ALL after infusion of universal TALEN gene-edited CAR T cells. SciTransl Med, 9(374), 1-8.

Qin H, Cho M, Haso W, et al. (2015). Eradication of B-ALL using chimeric antigen receptorexpressing T cells targeting the TSLPR oncoprotein. Blood, 126(5), 629-39.

Rafiq S, Hackett CS,Brentjens RJ (2019). Engineering strategies to overcome the current roadblocks in CAR T cell therapy.Nat Rev ClinOncol, 17(3), 147-67.

Rafiq S, et al. (2018). Targeted delivery of a PD-1-blocking scFv by CAR- T cells enhances anti- tumor efficacy in vivo. Nat Biotechnol, 36, 847-56.

Rafiq S, Purdon TJ, Daniyan AF, Koneru M, Dao T, Liu C, Scheinberg DA, Brentjens RJ. (2017). Optimized T-cell receptor-mimic chimeric antigen receptor $\mathrm{T}$ cells directed toward the intracellular WilmsTumor 1 antigenLeukemia, 31 (8), 1788-1797.

Ramanathan RK, et al. (2019). Phase IB/II randomized study of FOLFIRINOX plus pegylated recombinant human hyaluronidase versus FOLFIRINOX alone in patients with metastatic pancreatic adenocarcinoma: SWOG S1313. J ClinOncol, 37, 1062-9.

Ren J, Zhao Y (2017). Advancing chimeric antigen receptor T cell therapy with CRISPR/Cas9. Protein Cell, 8(9), 634-43.

Robertson MJ, et al. (2006). Clinical and biological effects of recombinant human interleukin-18 administered by intravenous infusion to patients with advanced cancer. Clin Cancer Res, 12, 4265-73. 
Rupp LJ, et al. (2017). CRISPR/Cas9-mediated PD-1 disruption enhances anti- tumor efficacy of human chimeric antigen receptor T cells. Sci Rep, 7, 737.

Sadelain M, Brentjens R, Riviere I (2013). The basic principles of chimeric antigen receptor design. Cancer Discov, 3(4), 388-98.

Sadelain M, Riviere I, Riddell S (2017). Therapeutic T cell engineering. Nature, 545, 423-31.

Schmidt-Wolf IG, Negrin RS, Kiem HP, Blume KG, Weissman IL (1991). Use of a SCID mouse/human lymphoma model to evaluate cytokine-induced killer cells with potent anti-tumor cell activity. Exp Med, 174, 139-49.

Scholler J, Brady TL, Binder-Scholl G, et al. (2012). Decade-long safety and function of retroviralmodified chimeric antigen receptor T cells. SciTransl Med, 4(132), 132ra53.

Sedimbi SK, Hagglof T, Karlsson MC (2013). IL-18 in inflammatory and autoimmune disease. Cell Mol Life Sci, 70, 4795-808.

Shah NN, et al. (2019). Results of a phase I study of bispecific anti- CD19, anti- CD20 chimeric antigen receptor (CAR) modified $\mathrm{T}$ cells for relapsed, refractory, nonHodgkin lymphoma. J ClinOncol, 37, 2510.

Simon S, Labarriere N (2017). PD-1 expression on tumorspecific T cells: friend or foe for immunotherapy? Oncoimmunology, 7, e1364828.

Siriwon N, et al. (2018). CAR- T cells surface- engineered with drug- encapsulated nanoparticles can ameliorate intratumoral T- cell hypofunction. Cancer Immunol Res, 6, 812-24.

Song DG, Powell DJ (2012). Pro- survival signaling via CD27 costimulation drives effective CAR T- cell therapy. Oncoimmunology, 1, 547-9.

Sridhar P, Petrocca F (2017). Regional delivery of chimeric antigen receptor (CAR) T- cells for cancer therapy. Cancers, 9, E92.

Suarez ER, et al. (2016). Chimeric antigen receptor T cells secreting anti- PD-L1 antibodies more effectively regress renal cell carcinoma in a humanized mouse model. Oncotarget, 7, 34341-55.

Tamada K, Geng D, Sakoda Y, Bansal N, Srivastava R, Li Z, Davila E (2012). Redirecting gene-modified $\mathrm{T}$ cells toward various cancer types using tagged antibodies. Clin Cancer Res, 18(23), 6436-45.

Tang L, et al. (2018). Enhancing T cell therapy through TCR- signaling-responsive nanoparticle drug delivery. Nat Biotechnol, 36, 707.

Tchou J, et al. (2017). Safety and efficacy of intratumoral injections of chimeric antigen receptor (CAR) T cells in metastatic breast cancer. Cancer Immunol Res, 5, 1152-61.

Tran E, et al. (2013). Immune targeting of fibroblast activation protein triggers recognition of multipotent bone marrow stromal cells and cachexia. J Exp Med, 210, 1125-35.

Tumaini B, Lee DW, Lin T, Castiello L, Stroncek DF, Mackall C, Wayne A, Sabatino M (2013). Simplified process for the production of anti-CD19-CAR-engineered T cells. Cytotherapy, 15(11), 1406-15.

Turtle CJ, Hay KA, Hanafi LA, Li D, Cherian S, Chen X, et al. (2017). Durable molecular remissions in chronic lymphocytic leukemia treated with CD19-specific chimeric antigen receptor-modified T cells after failure of ibrutinib. J ClinOncol, 35, 3010-20.

Urbanska K, Lanitis E, Poussin M, Lynn RC, Gavin BP, Kelderman S, Yu J, Scholler N, 
Powell DJ (2012). A universal strategy for adoptive immunotherapy of cancer through use of a novel T-cell antigen receptor. Cancer Res, 72(7), 1844-52.

Vidal-Vanaclocha F, et al. (2006). Clinical and experimental approaches to the pathophysiology of interleukin-18 in cancer progression. Cancer Metastasis Rev, 25, 417-34.

Vodnala SK, et al. (2019). T cell stemness and dysfunction in tumors are triggered by a common mechanism. Science, 363, eaau0135.

Wang E et al. (2015). Generation of potent T- cell immunotherapy for cancer using DAP12based, multichain, chimeric immunoreceptors. Cancer ImmunolRes, 3, 815-26.

Wang LC, et al. (2014). Targeting fibroblast activation protein in tumor stroma with chimeric antigen receptor $\mathrm{T}$ cells can inhibit tumor growth and augment host immunity without severe toxicity. Cancer Immunol Res, 2, 154-66.

Wilkie S, van Schalkwyk MC, Hobbs S, Davies D M, van der Stegen SJ, Pereira AC, Burbridge SE, Box C, Eccles SA, Maher J (2012). Dual targeting of ErbB2 and MUC1 in breast cancer using chimeric antigen receptors engineered to provide complementary signaling. J ClinImmunol, 32(5), 1059-70.

Wilkie S, et al. (2010). Selective expansion of chimeric antigen receptor- targeted T- cells with potent effector function using interleukin-4. J BiolChem, 285, 25538-44.

Wing A, et al. (2018). Improving CART- cell therapy of solid tumors with oncolytic virusdriven production of a bispecific T- cell engager. Cancer Immunol Res, 6, 605-16.

Xie YJ, Dougan M, Jailkhani N, Ingram J, Fang T, Kummer L, Momin N, Pishesha N, Rickelt S, Hynes RO, Ploegh H. (2019). Nanobody-based CAR T cells that target the tumor microenvironment inhibit the growth of solid tumors in immunocompetent mice. Proc Natl AcadSci USA,116(16), 7624-31.

Xu X, Gnanaprakasam JNR, Sherman J, Wang, RA (2019). metabolism toolbox for CAR T therapy. Front Oncol, 9, 322.

Yamamoto TN, et al. (2019). T cells genetically engineered to overcome death signaling enhance adoptive cancer immunotherapy. J Clin Invest, 129, 1551-65.

Yoon DH, Osborn MJ, Tolar J, Kim CJ (2018). Incorporation of immune checkpoint blockade into chimeric antigen receptor T cells (CAR- Ts): combination or built- in CAR- T. Int J MolSci, 19, E340.

Yu S, Li A, Liu Q, Li T, Yuan X, Han X, Wu K (2017). Chimeric antigen receptor T cells: A novel therapy for solid tumors. JHematolOncol, 10(1), 78.

Zhang C, Liu J, Zhong JF, Zhang X (2017). Engineering CAR-T cells. Biomarker Res, 5, 22.

Zhang G et al. (2014). Anti- melanoma activity of T cells redirected with a TCR- like chimeric antigen receptorSciRep, 4, 3571.

ZhaoY, Zheng Z, Cohen CJ, Gattinoni L, PalmerDC, Restifo NP, RosenbergSA, Morgan RA (2006). High-efficiency transfection of primary human and mouse $\mathrm{T}$ lymphocytes using RNA electroporation. MolTher, 13(1), 151-159. 